\title{
Mechanisms of $\mathrm{Na}^{+}-\mathrm{Ca}^{2+}$ Exchange Inhibition by Amphiphiles in Cardiac Myocytes: Importance of Transbilayer Movement
}

\author{
M. Keller, C. Pignier, E. Niggli, M. Egger \\ Department of Physiology, University of Bern, CH-3012 Bern, Switzerland
}

Received: 11 November 2003/Revised: 1 March 2004

\begin{abstract}
The membrane lipid environment and lipid signaling pathways are potentially involved in the modulation of the activity of the cardiac $\mathrm{Na}^{+}-\mathrm{Ca}^{2+}$ exchanger (NCX). In the present study biophysical mechanisms of interactions of amphiphiles with the NCX and the functional consequences were examined. For this purpose, intracellular $\mathrm{Ca}^{2+}$ concentration jumps were generated by laser-flash photolysis of caged $\mathrm{Ca}^{2+}$ in guinea-pig ventricular myocytes and $\mathrm{Na}^{+}-\mathrm{Ca}^{2+}$ exchange currents $\left(I_{\mathrm{Na} / \mathrm{Ca}}\right)$ were recorded in the whole-cell configuration of the patchclamp technique. The inhibitory effect of amphiphiles increased with the length of the aliphatic chain between $\mathrm{C}_{7}$ and $\mathrm{C}_{10}$ and was more potent with cationic or anionic head groups than with uncharged head groups. Long-chain cationic amines $\left(\mathrm{C}_{12}\right)$ exhibited a cut-off in their efficacy in $I_{\mathrm{Na} / \mathrm{Ca}}$ inhibition. Analysis of the time-course, comparison with the $\mathrm{Ni}^{2+}$-induced $I_{\mathrm{Na} / \mathrm{Ca}}$ block and confocal laser scanning microscopy experiments with fluorescent lipid analogs $\left(\mathrm{C}_{6^{-}}\right.$and $\mathrm{C}_{12^{2}}$ NBD-labeled analogs $)$ suggested that amphiphiles need to be incorporated into the membrane. Furthermore, NCX block appears to require transbilayer movement of the amphiphile to the inner leaflet ("flip"). We conclude that both, hydrophobic and electrostatic interactions between the lipids and the NCX may be important factors for the modulation by lipids and could be relevant in cardiac diseases where the lipid metabolism is altered.
\end{abstract}

Key words: Sodium-calcium exchange - Cardiac myocyte - Caged calcium - Excitation-contraction coupling - Heart failure-basic studies - Electrophysiology

Correspondence to: M. Egger; email: egger@pyl.unibe.ch

\section{Introduction}

The NCX is a membrane-spanning protein that is expressed in almost every mammalian cell and generates a bi-directional transport of $\mathrm{Na}^{+}$and $\mathrm{Ca}^{2+}$. In heart muscle cells it is established that under physiological conditions the NCX catalyzes the electrogenic countertransport of $3 \mathrm{Na}^{+}$for $1 \mathrm{Ca}^{2+}$ (Reeves \& Hale, 1984; Hinata et al., 2002; Kang \& Hilgemann, 2004, but see Fujioka, Komeda \& Matsuoka, 2000). The direction of the net ionic flux is determined by the membrane potential and by the transmembrane gradients for $\mathrm{Na}^{+}$and $\mathrm{Ca}^{2+}$ (see Egger \& Niggli, 1999a for a review). In cardiac myocytes this ion transport system plays a central role in the calcium homeostasis and in muscle relaxation (Bers, 2001). In addition, it may also be involved in excitation-contraction coupling (Leblanc \& Hume, 1990; Niggli, 1999). $\mathrm{Ca}^{2+}$, which is entering the cells via L-type $\mathrm{Ca}^{2+}$ channels during an action potential, has to be removed from the cytosol to ensure diastolic relaxation (Crespo, Grantham \& Cannell, 1990). It has been shown that the NCX can remove this "trigger" $\mathrm{Ca}^{2+}$ rapidly because of its high turnover rate (Bridge, Smolley \& Spitzer, 1990).

Mainly due to the lack of a highly specific inhibitor of NCX, its exact role in cardiac physiology as well as in pathophysiology are not yet completely understood. In addition, molecular details of the ion binding and translocation steps are not clear. How the exchanger protein functions at the molecular level and how it is regulated or modulated to ensure normal heart muscle function are the subject of intense investigations. In this context, it is not surprising that NCX was found to be a target of the cellular remodelling process during cardiac hypertrophy and failure (Hobai \& O'Rourke, 2000; Pogwizd et al., 2001; Gómez et al., 2002). Although a specific pharmacological agent for the exchanger is currently not 
available, it was found that NCX can be non-specifically blocked by di- and trivalent cations, by $\mathrm{pH}$, andby some organic agents, for example $3^{\prime}, 4^{\prime}$-dichlorobenzamil (DCB) and KB-R7943 (Egger \& Niggli, 1999a). Additionally, regulatory or modulatory factors (e.g., phosphorylation, changes in the cell membrane lipid compositions) may play a role in the regulation and/or "fine-tuning" of the exchanger function under physiological as well as under pathophysiological conditions (Hilgemann \& Collins, 1992; Collins \& Hilgemann, 1993).

Interestingly, changes in sarcolemmal fatty acid and lipid composition, which may affect NCX activity, have been observed during ischemia (Bersohn, Philipson \& Weiss, 1991; Van der Vusse, Van Bilsen, \& Reneman, 1994). As an example, lysophosphatidylcholine has been shown to be present in only small quantities in normal heart, whereas it is rapidly accumulated during ischemia (McHowatt et al., 1993; Carmeliet, 1999). Yet, the precise mechanism of the lipid metabolites targeting the NCX has not been determined conclusively. At pathophysiological concentrations, lysophosphatidylcholine can modify the function of the exchanger in lipid bilayer membranes, an effect that cannot be due to receptor-mediated mechanisms (Fukushima et al., 2001). These observations raise the question, to what extent direct effects of amphiphilic lipid metabolites on membrane protein functions should be ascribed to binding to the exchanger protein from the water phase and to what extent these compounds could act more indirectly, by altering the biophysical properties of the lipid phase of the cell membrane.

The goal of the present study was to examine the interactions of amphiphiles with NCX more directly. For this purpose, intracellular $\mathrm{Ca}^{2+}$ concentration jumps were generated by laser-flash photolysis of caged $\mathrm{Ca}^{2+}$ in guinea-pig ventricular myocytes. The resulting $\mathrm{Na}^{+}-\mathrm{Ca}^{2+}$ exchange currents were recorded in the whole-cell configuration of the patch-clamp technique. Because of the complexity of the potentially involved cellular lipid signalling pathways a range of fluorescent-labelled and simple amphiphilic substances with different carbon chain lengths and different head groups was used to explore biophysical interactions with NCX. We found that NCX current can be blocked with amphiphiles with an efficacy that varies with their carbon chain length. In addition, positively and negatively charged head groups appeared to be more effective blockers than those carrying no charge. We conclude that in addition to hydrophobic and electrostatic interactions, which may be important factors for NCX modulation or regulation by lipids, charged lipids could also directly interact with the exchanger, or alternatively via NCX associated molecules. Moreover, the analysis of the time-course of inhibition and recovery of NCX current by using fluorescently-labelled phospholipid analogs and various aliphatic amphiphiles suggested that amphiphiles need to be incorporated and to flip to the inner leaflet of the membrane to exert their activity on NCX, possibly by interacting with the intracellular loop of NCX, which is known to be the target of many modulatory mechanisms (Matsuoka et al., 1993 1997). Preliminary results have been presented to the Biophysical Society in abstract form (Egger \& Niggli, 1999b).

\section{Materials and Methods}

\section{Cell Isolation and Solutions}

Cardiac ventricular myocytes were isolated from guinea-pig hearts using an enzymatic dispersion technique (Mitra \& Morad, 1985). The experiments were performed according to the Swiss Animal Protection Law and with the permission of the State Veterinary Office, Bern, Switzerland. After heparinization, the guinea-pigs were killed by cervical dislocation and the heart was quickly removed and mounted on a Langendorff apparatus. The heart was perfused for $5 \mathrm{~min}$ at $37{ }^{\circ} \mathrm{C}$ with a nominally $\mathrm{Ca}^{2+}$-free perfusion solution containing (in $\mathrm{mM}$ ): $\mathrm{NaCl} 135 ; \mathrm{KCl} 5.4 ; \mathrm{MgCl}_{2}$ 1; $\mathrm{NaH}_{2} \mathrm{PO}_{4}$ 0.33; HEPES 5; glucose 11; pH adjusted to 7.4 with $\mathrm{NaOH}$. Collagenase B $(0.4 \mathrm{mg} / \mathrm{ml}$, Boehringer Mannheim, Rotkreuz, Switzerland) and protease type XIV $(0.04 \mathrm{mg} / \mathrm{ml}$, Sigma, Buchs, Switzerland) were used for the enzymatic digestion and added to the perfusion solution for $6 \mathrm{~min}$. After the heart became flaccid, it was removed and placed in a perfusion solution containing $200 \mu \mathrm{M} \mathrm{CaCl}_{2}$, then cut into small pieces and placed on a rocking table to allow for dissociation of the tissue. Cells were taken from the supernatant and transferred into a recording chamber with a glass coverslip and mounted onto the stage of an inverted microscope (Diaphot TMD, Nikon, Küsnacht, Switzerland). Isolated $\mathrm{Ca}^{2+}$-resistant cardiac myocytes were constantly superfused with extracellular solution containing (in $\mathrm{mm}$ ): $\mathrm{NaCl}$ 140; $\mathrm{KCl} 5 ; \mathrm{CaCl}_{2}$ 1.8; $\mathrm{CsCl}_{2}$ 1.0, $\mathrm{BaCl}_{2}$ 0.5; HEPES 10; glucose 10; $\mathrm{pH}$ adjusted to 7.4 with $\mathrm{NaOH}$. All experiments were performed at room temperature $\left(20-22^{\circ} \mathrm{C}\right)$.

\section{AmphiphiLes}

Heptylamine, octylamine, decylamine, dodecylamine, heptanol, octanol, dodecanol, oenantic acid, caprinic acid, lauric acid were purchased from Fluka (Buchs, Switzerland), decanol and acetylcarnitine from Sigma (Buchs, Switzerland). Stock solutions of these compounds were made in water or ethanol, according to the instructions of the manufacturers. 1-Oleyl-2-hydroxy-sn-glycero-3phosphate (LPA) and 1-palmitoyl-2-hydroxy-sn-glycero-3-phosphocholine (LPC) were purchased from Avanti Polar Lipids (Alabaster, $\mathrm{AL}$ ) and stock solutions were made in chloroform. $\mathrm{NBDC}_{6}$-HPC (2-(6-(7-nitrobenz-2-oxa-1,3-diazol-4-yl)amino)hexanoyl-1-hexadecanoyl-sn-glycero-3 phosphocholine) and $\mathrm{NBDC}_{12}$ HPC (2-(12-(7-nitrobenz-2-oxa-1,3-diazol-4-yl)amino)dodecanoyl1-hexadecanoyl-sn-glycero-3-phosphocholine) were purchased from Molecular Probes (Eugene, OR) diluted in chloroform. Drugs were delivered to the cells by means of a gravity-driven rapid superfusion system located in the vicinity $(\sim 200 \mu \mathrm{m})$ of the cell examined. For controls for solubility, the octanol partition coefficients were obtained by using the online version of LogKow Program (http://esc-plaza.syrres.com/interkow/logkow. htm). 


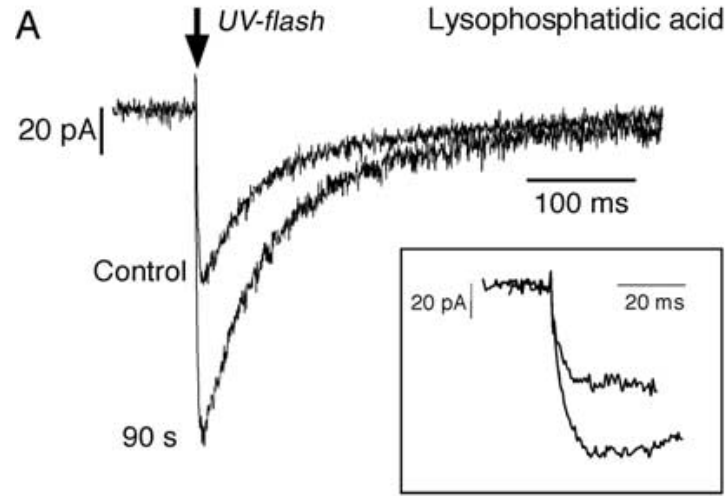

B L-palmitoyl-lysophosphatidylcholine

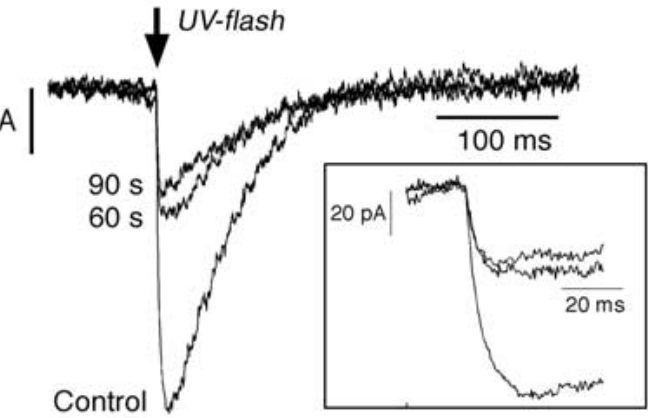

C

$20 \mathrm{pA}$

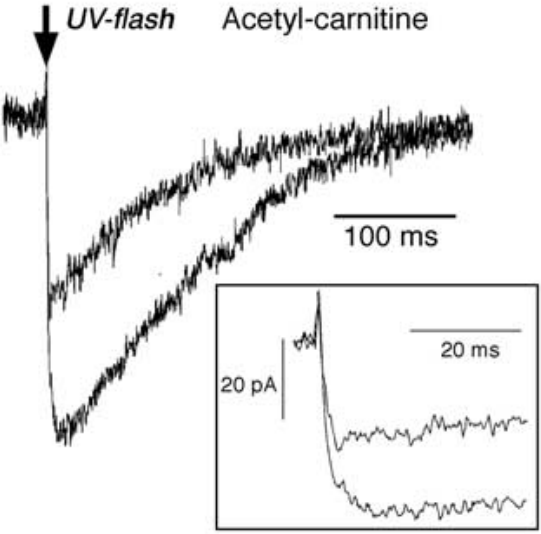

Fig. 1. Reduced $\mathrm{Na}^{+}-\mathrm{Ca}^{2+}$ exchange function in myocytes after naturally occurring amphiphile treatment.(A) $I_{\mathrm{Na} / \mathrm{Ca}}$ stimulation after $90 \mathrm{~s}$ treatment with $3 \mu \mathrm{m}$ lysophophatidic acid (LPA, 1-oleyl2-hydroxy-sn-glycero-3-phosphate, a naturally occurring amphiphile). (B) $I_{\mathrm{Na} / \mathrm{Ca}}$ block after $60 \mathrm{~s}$ and $90 \mathrm{~s}$ treatment with $3 \mu \mathrm{M}$ lysophosphatidylcholine (LPC, 1-palmitoyl-2-hydroxy- $s n$-glycero3-phosphocholine). (C) $I_{\mathrm{Na} / \mathrm{Ca}}$ block after $80 \mathrm{~s}$ treatment with $50 \mu \mathrm{M}$ acetylcarnitine. $I_{\mathrm{Na} / \mathrm{Ca}}$ was induced by an intracellular $\mathrm{Ca}^{2+}$ jump due to laser flash photolysis of DM-nitrophen and was recorded at $-40 \mathrm{mV}$. As shown in the insets, $I_{\mathrm{Na} / \mathrm{Ca}}$ can be separated into two components, the fast one (within the first $2 \mathrm{~ms}$ after the flash), which is due to the $\mathrm{Ca}^{2+}$ photo-release, and the slow component due to the subsequent CICR. Please note that unlike in all other experiments, these cells were not pre-treated with thapsigargin. $(D)$ The time course of $I_{\mathrm{Na} / \mathrm{Ca}}$ stimulation and inhibition by: $3 \mu \mathrm{M} \mathrm{LPA} \mathrm{( \square ),} 3 \mu \mathrm{M}$ LPC $(\bullet), 50 \mu \mathrm{M}$ acetylcarnitine $(\bullet)$, control $(\bigcirc)$. The data were

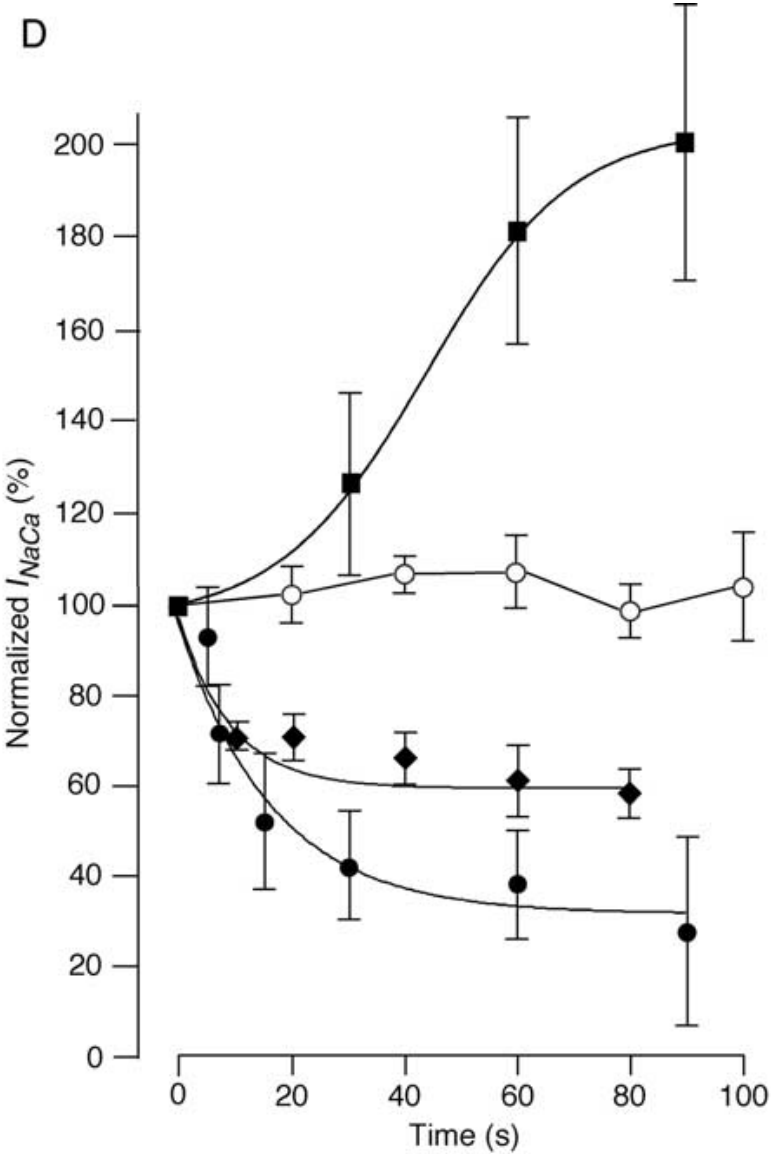

E

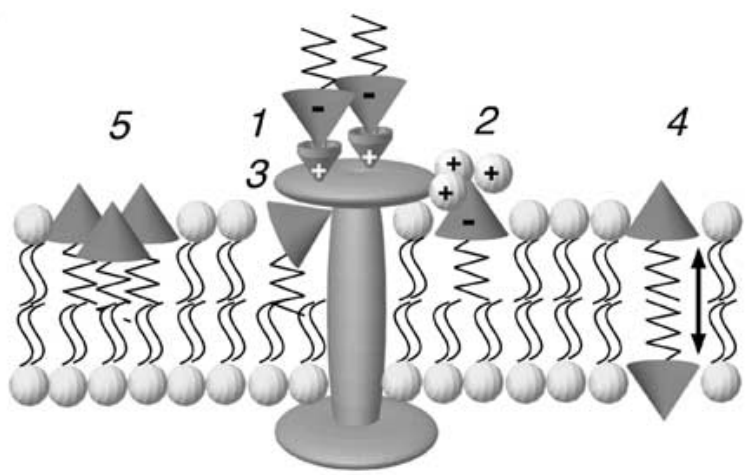

fitted with a monoexponential function (LPC: $\tau=17 \pm 5.1 \mathrm{~s}, n=5$; acetylcarnitine: $9.2+2.6 \mathrm{~s}, n=5$ ). (E) Biophysical interaction of amphiphiles with biomembranes and the $\mathrm{Na}^{+}-\mathrm{Ca}^{2+}$ exchanger. Amphiphiles can interact with the $\mathrm{Na}^{+}-\mathrm{Ca}^{2+}$ exchanger in different ways: (1) by interactions of amphiphiles with the NCX protein from the water phase of the extracellular space (reversible binding by Van der Waals or steric interactions); (2) by incorporation of the amphiphiles into the membrane bilayer and interaction with the NCX protein via modification of surface charge, which could lead to changes in local ion concentration (e.g., $\mathrm{Ca}^{2+}$ accumulation); (3) by incorporation of the amphiphiles and subsequent lipid-protein interaction from the lipid phase; (4) after a flip to the inner leaflet of the membrane, interactions $1-3$ are also possible from the inner side of the membrane; (5) the NCX could also be affected via lipid-phase transitions or membrane lipid separations (e.g., "lipid rafts", Simons \& Toomre, 2000). 

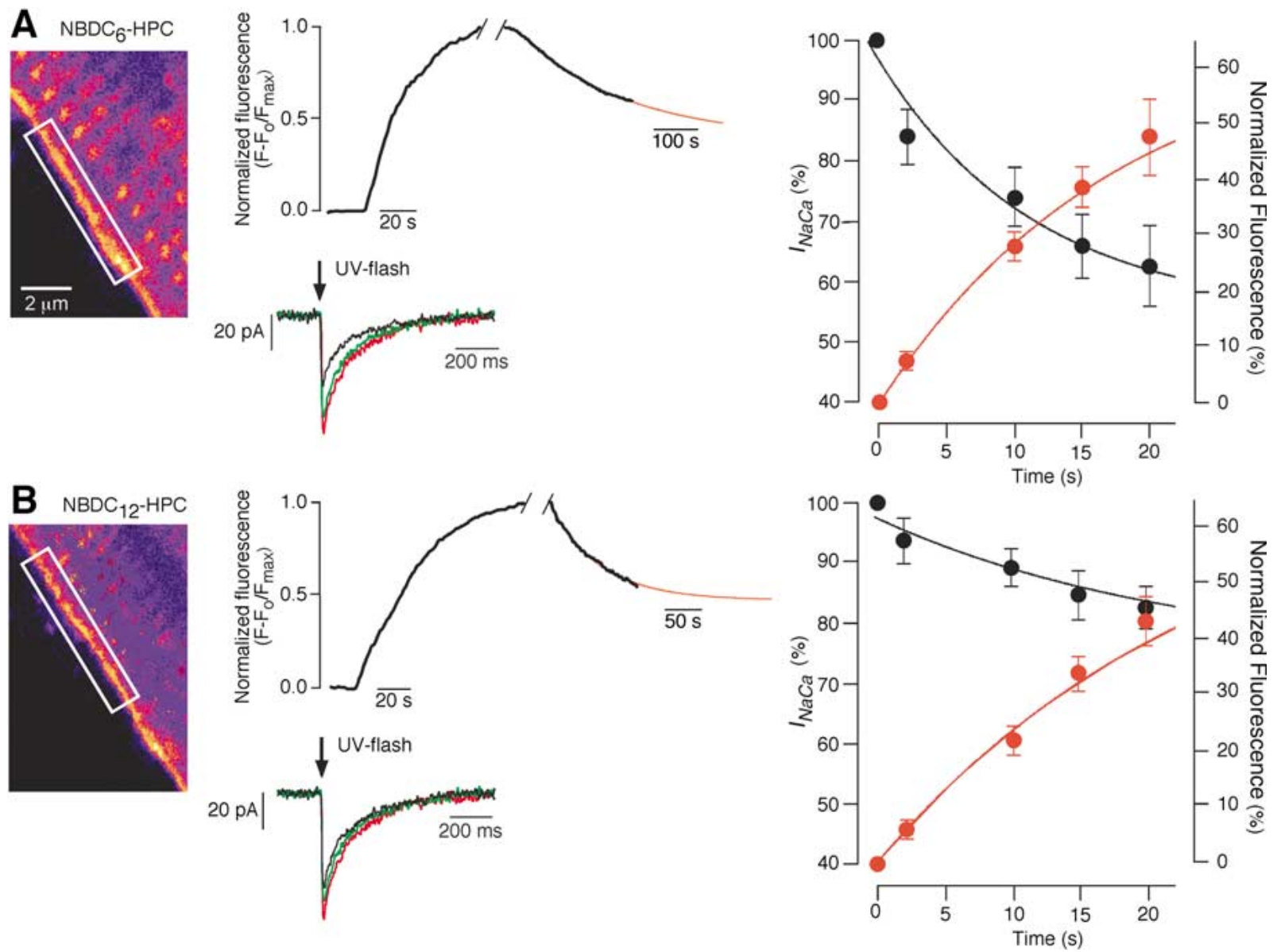

Fig. 2. $I_{\mathrm{Na} / \mathrm{Ca}}$ affected by fluorescent lipid probes $\mathrm{NBD}-\mathrm{C}_{6}-\mathrm{HPC}$ and NBD-C 12 -HPC. From left to right: Confocal image of a single ventricular myocyte stained with the fluorescent lipid probe NBD$\mathrm{C}_{6}$-HPC $(A)$ or NBD-C ${ }_{12}$-HPC $(B)$ and the time course of incorporation and washout measured in a region of interest (white rectangle) as changes in the fluorescence intensity (middle) recorded with a confocal laser scanning microscope and expressed as $\left(F-F_{\mathrm{o}}\right) /$

\section{UV-Laser Flash Photolysis}

Single UV flashes or flash trains with a duration of 1-10 s were applied to photolyze intracellular DM-nitrophen in an epi-illumination microscope arrangement and were generated with a frequency-tripled Nd:YAG laser (Surelite-II, Continuum, Santa Clara, CA; wavelength $355 \mathrm{~nm}$; double-pulse mode, $20 \mathrm{~ns}$ each pulse, $40 \mu$ s separation, maximum energy $20.7 \mathrm{~mJ}$ ). The UV-line of the laser beam was reflected by a series of 4 dichroic mirrors to remove infrared and green laser light. The beam was delivered to the epi-illumination port of the inverted microscope with a liquidlight guide; after reflection by a dichroic mirror the light passed through the microscope objective to generate a homogeneous illumination of the entire visible field.

\section{Voltage Clamp and Data Analysis}

The $I_{\mathrm{Na} / \mathrm{Ca}}$ was recorded in the whole-cell configuration of the patch-clamp technique using an Axopatch-lD voltage-clamp amplifier (Axon Instruments, Foster City, CA) driven by a data acquisition board (software developed under LabView, both from National Instruments, Austin, TX) running on an Apple Power PC

$F_{\text {max }}$; the photolytically triggered $I_{\mathrm{Na} / \mathrm{Ca}}$ (below; red: control; green: after $2 \mathrm{~s}$; black: after $10 \mathrm{~s}$ ) at $-40 \mathrm{mV}$, and (right) the time course of fluorescence change (red) and the corresponding $I_{\mathrm{Na} / \mathrm{Ca}}$ block (black) during NBD-C 6 -HPC and NBD-C 12 -HPC $(100 \mu \mathrm{M})$ superfusion. (Fluorescence increase: NBD-C 6 -HPC: $\tau=13.06 \pm 3.1 \mathrm{~s}$; NBD-C 12 -HPC: $\tau=17.5 \pm 6.7 \mathrm{~s})$ The data were fitted with a monoexponential function (mean $\pm \mathrm{SEM}, n=7-10$ ).

8100/100 (Apple Computer, Cupertino, CA). Synchronization between the flash, control of the membrane voltage and the data acquisition and current measurements (digitized at $5000 \mathrm{~Hz}$ ) was performed by triggering via an optical fiber. Micropipettes were pulled from filamented borosilicate glass capillaries (GC 150F, Clark Electromedical Instruments, Pangbourne, UK) on a horizontal puller (DMZ, Zeitz Instrumente, Augsburg, Germany) with a final tip diameter of 1-2 $\mu \mathrm{M}$ and a resistance of 1-2.5 M $\Omega$. For $I_{\mathrm{Na} / \mathrm{Ca}}$ and L-type $\mathrm{Ca}^{2+}$ current $\left(I_{\mathrm{Ca}-\mathrm{L}}\right)$ measurements the pipette filling solution contained (in mM): CsAsp 120; TEA-C1 20; HEPES 20; $\mathrm{K}_{2}$ ATP 5, $\mathrm{CaCl}_{2}$ 0.5; $\mathrm{Na}_{4}$-DM-nitrophen 2, pH 7.2 (adjusted with $\mathrm{CsOH}$ ). Thapsigargin was purchased from Alomone Labs., Jerusalem, Israel. $I_{\mathrm{Na} / \mathrm{Ca}}$ was activated by means of a UV flash at $-40 \mathrm{mV}$ and the peak $I_{\mathrm{Na} / \mathrm{Ca}}$ amplitude was determined from the mean current value of five data points around the most inward current sample in the record (after baseline correction). Trains of L-type calcium currents were applied by depolarizing steps from $-40 \mathrm{mV}$ to $0 \mathrm{mV}$ during $200 \mathrm{~ms}$ at a frequency of $1 \mathrm{~Hz}$. Data were analyzed using Igor Pro software (WaveMetrics, Lake Oswego, OR) and results are expressed as mean \pm SEM. Statistical analysis was performed by using an appropriate Student's $t$-test. Significance is given as $P<0.05$ or $<0.1$, as indicated in the figure legends. 
A

\section{$I_{\mathrm{NaCa}}$}
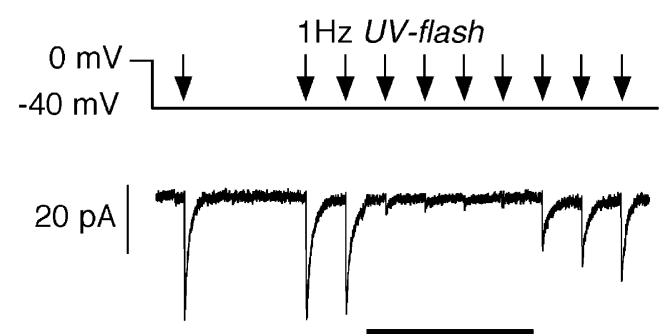

$5 \mathrm{mM} \mathrm{Ni}^{2+}$

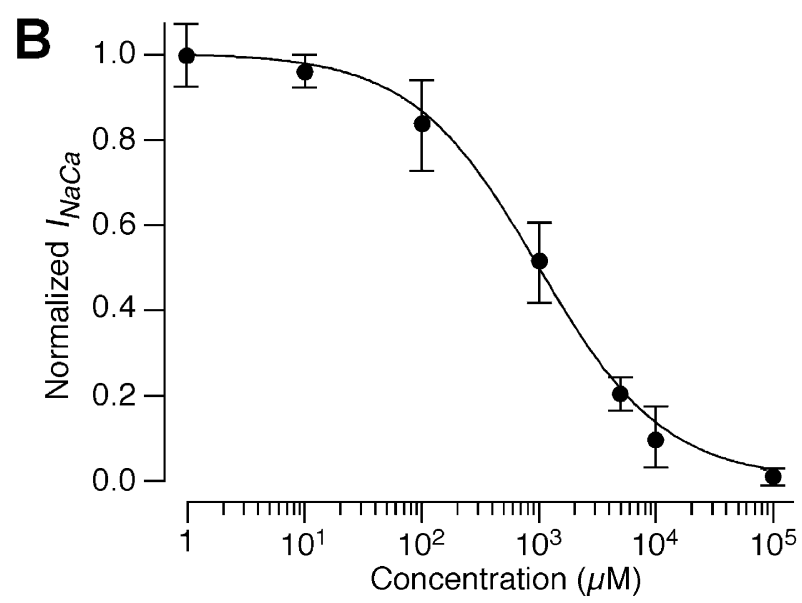

Fig. 3. $\mathrm{Ni}^{2+}$-induced $I_{\mathrm{Na} / \mathrm{Ca}}$ block. (A) Applied voltage protocol to obtain sodium-calcium exchange currents $I_{\mathrm{Na} / \mathrm{Ca}}$ induced by UV flash trains $(1 \mathrm{~Hz})$ and the corresponding $I_{\mathrm{Na} / \mathrm{Ca}}$ recorded in the whole-cell configuration of the patch-clamp technique. Superfusion duration is indicated by the horizontal bar and was $3 \mathrm{~s}$ and $4 \mathrm{~s}$, respectively. (B) Dose-response curve for $\mathrm{Ni}^{2+}$-induced $I_{\mathrm{Na} / \mathrm{Ca}}$

\section{Confocal Microscopy}

The setup for fluorescence measurements was based on a confocal laser scanning microscope (MRC 1000, Biorad, Glattbrugg, Switzerland). NBD- $\mathrm{C}_{6}-\mathrm{HPC}$ and $\mathrm{NBD}-\mathrm{C}_{12}-\mathrm{HPC}$ were excited with the $488 \mathrm{~nm}$ line of an argon laser (Model 5000, Ion Laser Technology, Salt Lake City, UT) at $150 \mu \mathrm{W}$ intensity on the cell. Fluorescence emission was detected at $>525 \mathrm{~nm}$. The intensity of fluorescence increase above background for each region of interest was divided by the maximal fluorescence giving the fluorescence ratio $\left(F-F_{\mathrm{o}}\right) /$ $F_{\max }$.

\section{Results}

\section{Lysolipid Sensitivity of $\mathrm{Na}^{+}-\mathrm{Ca}^{2+}$ Exchange CuRRENTS}

Intracellular $\mathrm{Ca}^{2+}$ jumps have been shown to activate the $\mathrm{Ca}^{2+}$ efflux mode of NCX, thereby producing a net inward current $\left(I_{\mathrm{Na} / \mathrm{Ca}}\right.$, Niggli \& Lederer, 1993), such as the example recorded at $-40 \mathrm{mV}$ shown in Fig. $1 A, B$. The rapid activation (2 ms) of $I_{\mathrm{Na} / \mathrm{Ca}}$ in response to the flash confirmed that the
C I $\quad I_{C-L}$
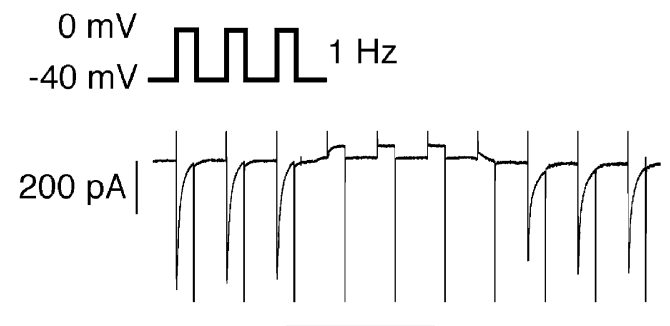

$5 \mathrm{mM} \mathrm{Ni}^{2+}$

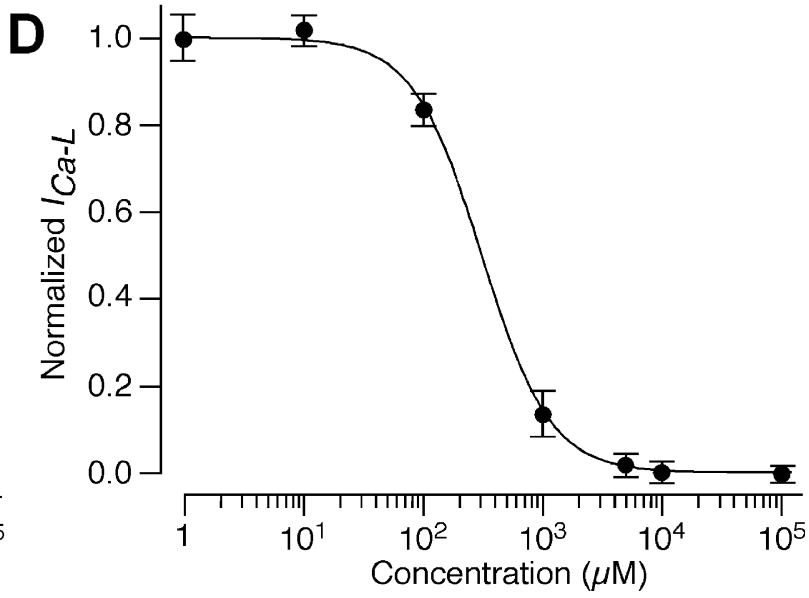

block. (C) Applied voltage protocol elicited L-type calcium currents $\left(I_{\mathrm{Ca}-\mathrm{L}}\right.$, at $0 \mathrm{mV}$, from a holding potential of $-40 \mathrm{mV}, 200 \mathrm{~ms}$ duration, $1 \mathrm{~Hz}$ ) and the corresponding $I_{\mathrm{Ca}-\mathrm{L}}$, trace below. $(D)$ Dose-response curve for $\mathrm{Ni}^{2+}$-induced $I_{\mathrm{Ca}-\mathrm{L}}$ block). The SRfunction in isolated cardiac myocytes was suppressed with $0.1 \mu \mathrm{M}$ thapsigargin.

current was due to the photorelease from DM-nitrophen, followed by a more slowly activating component, resulting from $\mathrm{Ca}^{2+}$-induced $\mathrm{Ca}^{2+}$ release (CICR; insets: expanded and superimposed $I_{\mathrm{Na} / \mathrm{Ca}}$ ). Figure $1 A$ shows superimposed traces of $I_{\mathrm{Na} / \mathrm{Ca}}$ in control conditions and after $3 \mu \mathrm{M}$ lysophosphatidic acid (LPA, $\mathrm{C}_{18: 0}$ ) treatment. LPA below the critical micelle concentration (Bergmann, Ferguson \& Sobel, 1981) has been found to approximately double $I_{\mathrm{Na} / \mathrm{Ca}}$ after $90 \mathrm{~s}$ (Fig. $1 A, D$ ) in a complex time-course. Conversely, L-palmitoyl-lysophosphatidylcholine (LPC, $\mathrm{C}_{16: 0}$, Fig. $1 B, D$ ) and $50 \mu \mathrm{M}$ acetylcarnitine (AC, Fig. 1C,D) treatment has been found to significantly block $I_{\mathrm{Na} / \mathrm{Ca}}$ by about $60 \%$ and $40 \%$ after $60 \mathrm{~s}$, respectively. The time-course of NCX block followed a monoexponential function with a time constant of $\approx 17 \mathrm{~s}$ and of $\approx 9 \mathrm{~s}$, respectively (Fig. 1D). The nature of this functional NCX block as well as stimulation is not clear because LPC, AC and LPA could act on the NCX protein via direct biophysical mechanisms or indirectly via intracellular lipid-sensitive signaling pathways possibly targeting NCX and the CICR mechanism (Xu, 2002). 
Table 1. Effect of chain length and charge of amphiphiles on NCX block

\begin{tabular}{|c|c|c|c|c|}
\hline Chain length & Amphiphile & $\begin{array}{l}\text { Max. } \\
I_{\mathrm{NaCa}} \text { inhibition }(\%)\end{array}$ & $I C_{50}\left(I_{\mathrm{NaCa}}\right)$ & $\begin{array}{l}\text { Time course of } I_{\mathrm{NaCa}} \text { inhibition, } \\
\tau \text { fast } \tau \text { slow (s) }\end{array}$ \\
\hline \multicolumn{5}{|c|}{$\begin{array}{l}\text { Ionic: Positively } \\
\text { charged }\end{array}$} \\
\hline $\mathrm{C}-7$ & Heptylamine & 100 & $2.59 \pm 0.84 \mathrm{mM}, n=11$ & $1.7 \pm 1.05 / 21.9 \pm 6.8, n=11$ \\
\hline C-8 & Octylamine & 100 & $115 \pm 23 \mu \mathrm{M}, n=6$ & $4.9 \pm 2.3 / 19.3 \pm 4.7, n=6$ \\
\hline $\mathrm{C}-10$ & Decylamine & 100 & $75.7 \pm 1.9 \mu \mathrm{M}, n=10$ & $2.7 \pm 1.2 / 11.9 \pm 5.1, n=10$ \\
\hline $\mathrm{C}-12$ & Dodecylamine & $60.3 \pm 11.5, n=5$ & $18.4 \pm 3.45 \mu \mathrm{M}, n=10$ & $74.6 \pm 3.6, n=5^{\#}$ \\
\hline \multicolumn{5}{|c|}{$\begin{array}{l}\text { Ionic: Negatively } \\
\text { charged }\end{array}$} \\
\hline C-7 & Oenantic acid & 100 & $0.29 \pm 0.17 \mathrm{mM}, n=5$ & n.d. \\
\hline $\mathrm{C}-10$ & Caprinic acid & $50.4 \pm 7.2, n=3$ & n.d. $(500 \mu \mathrm{M})$ & n.d. \\
\hline $\mathrm{C}-12$ & Lauric acid & $66.2 \pm 11, n=4$ & n.d. $(500 \mu \mathrm{M})$ & n.d. \\
\hline \multicolumn{5}{|l|}{ Non-ionic } \\
\hline $\mathrm{C}-7$ & Heptanol & $32.7 \pm 7.5, n=10$ & $0.74 \pm 0.10 \mathrm{mM}, n=10$ & $48.7 \pm 16.3, n=5^{\#}$ \\
\hline C-8 & Octanol & $37.1 \pm 9.2, n=5$ & n.d. $(1 \mathrm{mM})$ & $22.2 \pm 15.7, n=4^{\#}$ \\
\hline C-10 & Decanol & 0 & n.d. $(0.01-10 \mathrm{mM})$ & n.d. \\
\hline $\mathrm{C}-12$ & Dodecanol & 0 & n.d. $(0.01-10 \mathrm{mM})$ & n.d. \\
\hline
\end{tabular}

n.d., could not be determined; concentration range in parentheses

${ }^{\text {\#No fast component }}$

Like every transmembrane protein, NCX molecules could be affected by amphiphiles, such as shortor long-chain alcohols, fatty acids or phospholipids, by several fundamentally different mechanisms (Fig. 1E; for details see Discussion). In the present study, some of these potentially important mechanisms involved in NCX interaction were examined in more detail.

\section{CORRELATION BETWEEN LIPID INCORPORATION AND Time Course of NCX Block}

For a less complex experimental approach and to separate biophysical from intracellular pathway interactions mentioned above, myocytes were incubated with $0.1 \mu \mathrm{M}$ thapsigargin for $30 \mathrm{~min}$ to block the $\mathrm{SR} \mathrm{Ca}^{2+}$ pump and to exclude interference from CICR with the photolytically generated $\mathrm{Ca}^{2+}$ concentration jumps (Kirby et al., 1992). In addition, $I_{\mathrm{Na} / \mathrm{Ca}}$ measurements were combined with confocal microscopy experiments using fluorescently labelled phospholipid analogs presenting different chain lengths $\left(\mathrm{NBDC}_{6}-\mathrm{HPC}\right.$ and $\mathrm{NBDC}_{12}-\mathrm{HPC}$, Fig. $2 A$, $B)$ to directly follow the uptake of these amphiphiles into the membrane. As shown in Fig. 2, superfusion with $100 \mu \mathrm{M}$ of the fluorescent lipid probes was followed by an increase in fluorescence preferentially located to the plasmalemma. Although both fluorescent dyes presented different carbon chain lengths $\left(\mathrm{C}_{6}\right.$ and $C_{12}$ ) when corrected for background fluorescence and normalized for the maximal intensity $\left(\left(F-F_{\mathrm{o}}\right) /\right.$ $\left.F_{\text {max }}\right)$, the time constants for the uptake were comparable $(\approx 15 \mathrm{~s})$. Whereas the fluorescence started to increase with the beginning of the superfusion, the decline due to washout appeared to be delayed and the time to reach half-recovery was about 20 -fold slower than for loading (time to reach half-recovery: NBD-C 6 -HPC: $\quad 350.5 \pm 30.2 \mathrm{~s}$; $\quad$ NBD-C 12 -HPC: $187.1 \pm 11 \mathrm{~s}) . \mathrm{NBD}-\mathrm{C}_{6}-\mathrm{HPC}$ treatment exhibited significant time-dependent $I_{\mathrm{Na} / \mathrm{Ca}}$ inhibition of about $45 \%$ after $20 \mathrm{~s}(\tau \approx 11.2 \mathrm{~s}$, Fig. $2 A)$. In comparison, NBD-C $\mathrm{C}_{12}$-HPC showed a less pronounced inhibition of about $15 \%$ after $20 \mathrm{~s}(\tau \approx 22.5 \mathrm{~s}$, Fig. $2 B)$. Although the absolute final concentration of each fluorescent dye accumulated in the membrane cannot be compared directly, the results suggest that the difference in chain length between NBD-C ${ }_{6}$-HPC and NBD-C $\mathrm{C}_{12}$-HPC did not dramatically affect their ability and kinetics for the incorporation into the membrane. In addition, the time course of membrane fluorescence increase was similar to the time course of $I_{\mathrm{Na} / \mathrm{Ca}}$ inhibition for $\mathrm{C}_{6}$ fluorescence phospholipid analogs. This suggests that incorporation of this amphiphile was, in fact, required before functional NCX block could occur. The long-chain phospholipid analog $\left(\mathrm{C}_{12}\right)$ exhibited a lower potency for $I_{\mathrm{Na} / \mathrm{Ca}}$ inhibition, associated with an extended time course for the $I_{\mathrm{Na} / \mathrm{Ca}}$ block.

In the following experiments, the time course and efficacy of $I_{\mathrm{Na} / \mathrm{Ca}}$ block induced by simple aliphatic amphiphiles and a divalent ion $\left(\mathrm{Ni}^{2+}\right)$ were used to distinguish between different biophysical interactions on NCX protein.

\section{RAPID $\mathrm{Na}^{+}-\mathrm{Ca}^{2+}$-Exchange CURRENT Inhibition: Nickel BLOCK}

Extracellular nickel is the divalent cation most widely used to block $I_{\mathrm{Na} / \mathrm{Ca}}$ (Kimura, Miyamae \& Noma, 1997). It is assumed that $\mathrm{Ni}^{2+}$ blocks NCX function by binding to one of the extracellular cation binding sites on the protein, followed by suppression of 


\section{A a}

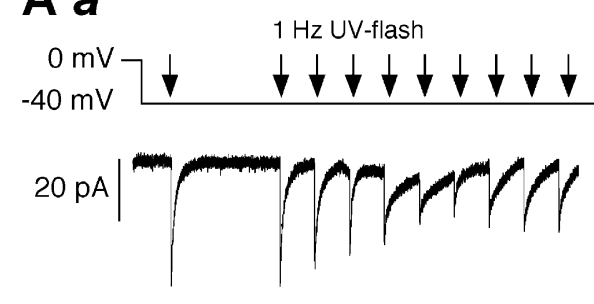

5 mM Heptylamine

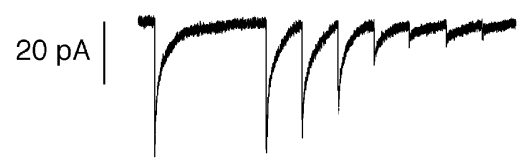

$100 \mu \mathrm{M}$ Decylamine b

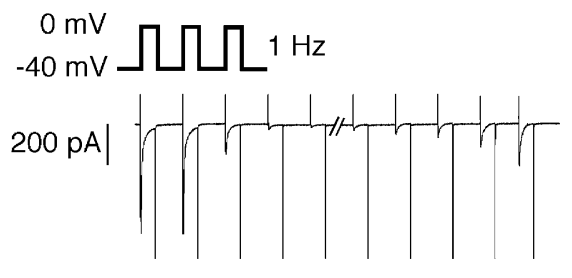

5 mM Heptylamine

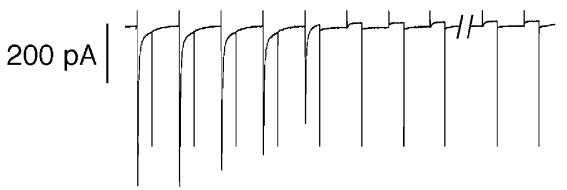

$100 \mu \mathrm{M}$ Decylamine

B

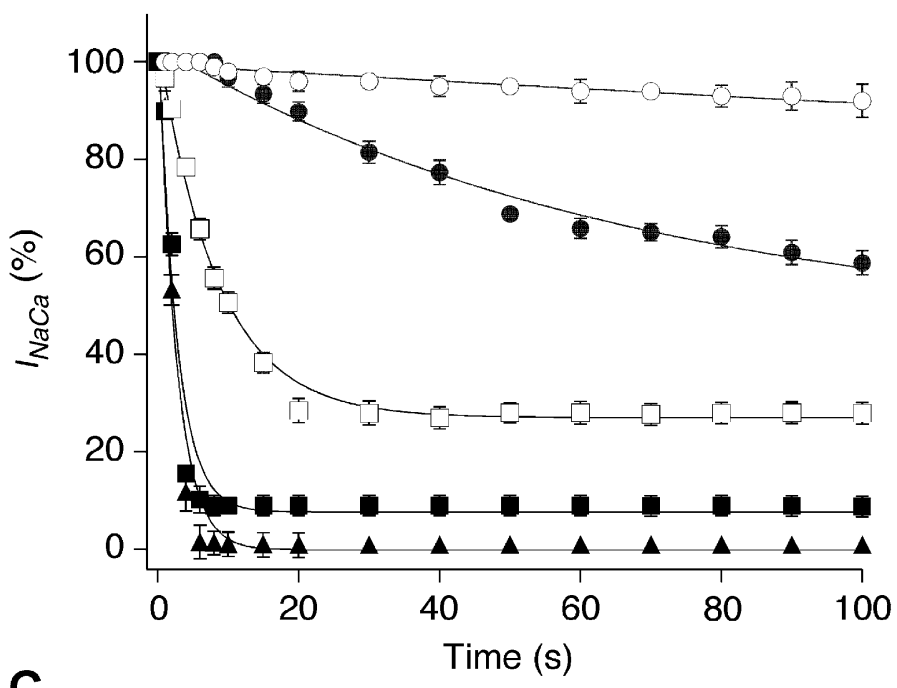

C

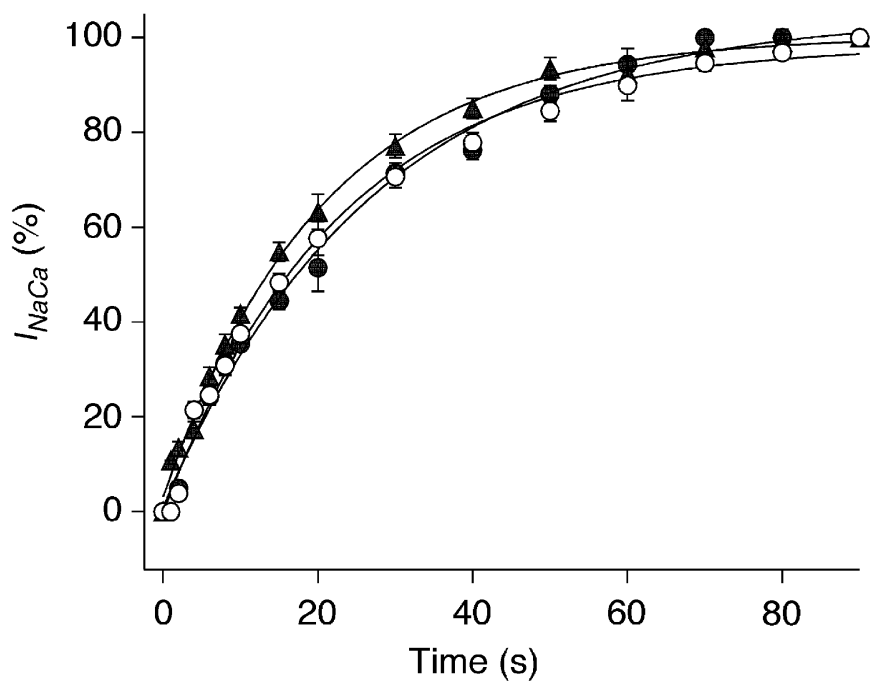

Fig. 4. Time course of $I_{\mathrm{Na} / \mathrm{Ca}}$ inhibition induced by heptylamine and decylamine. (A) Applied voltage protocols and the corresponding $I_{\mathrm{Na} / \mathrm{Ca}}(A a)$ and $I_{\mathrm{Ca}-\mathrm{L}}(A b)$ recorded in the whole-cell configuration of the patch-clamp technique. $I_{\mathrm{Na} / \mathrm{Ca}}$ was obtained at $-40 \mathrm{mV}$ by UV flash trains $(1 \mathrm{~Hz})$ and $I_{\text {Ca-L }}$ was elicited at $0 \mathrm{mV}$ (from a holding potential of $-40 \mathrm{mV}$, $200 \mathrm{~ms}$ duration) at $1 \mathrm{~Hz}$. Double slashes shown for $I_{\mathrm{Ca}-\mathrm{L}}$ indicate time gap for clarity. Superfusion duration is indicated by horizontal bar. The SR-function in isolated cardiac myocytes was suppressed with $0.1 \mu \mathrm{m}$ thapsigargin. Time course of inhibition $(B)$ and recovery of $I_{\mathrm{Na} / \mathrm{Ca}}$ (C) by decylamine treatment. Values for the time course of inhibition and for recovery are expressed as percentage of $I_{\mathrm{Na} / \mathrm{Ca}}$ amplitude in control conditions and after steadystate inhibition, respectively. Decylamine: $1 \mu \mathrm{M}(\bigcirc), 10 \mu \mathrm{M}(\bullet)$, $100 \mu \mathrm{m}(\square), 500 \mu \mathrm{m}(\mathbf{\square}), 1 \mathrm{~mm}(\mathbf{\Lambda})$. Error bars represent mean \pm SEM $(n=10)$. 
electrogenic charge transport (Egger et al., 1999). Under this assumption, the inhibition and recovery of $I_{\mathrm{Na} / \mathrm{Ca}}$ by $\mathrm{Ni}^{2+}$ would therefore only be limited by the time for the exchange of the solution around the cell and inside the T-tubules (Blatter \& Niggli, 1998) and thus the time-course of the $\mathrm{Ni}^{2+}$-induced NCX block can be assessed as a reference for rapid NCX interactions by direct $\mathrm{Ni}^{2+}$ binding from the surrounding water phase. The use of UV-laser flash trains $(1 \mathrm{~Hz}$, Fig. 3A) allowed us to conveniently examine the time course of the $I_{\mathrm{Na} / \mathrm{Ca}}$ block. Rapid superfusion ( $\tau$ of solution change $<300 \mathrm{~ms}$ ) of $5 \mathrm{mM} \mathrm{Ni}^{2+}$ completely and immediately abolished the inward $I_{\mathrm{Na} / \mathrm{Ca}}$. The dose-response curve $\left(I C_{50}: 0.93 \pm 0.073 \mathrm{mM}\right.$, $n=5-12)$ of $\mathrm{Ni}^{2+}$-induced $I_{\mathrm{Na} / \mathrm{Ca}}$ block is shown in Fig. $3 B$. Upon wash-out of $\mathrm{Ni}^{2+}, I_{\mathrm{Na} / \mathrm{Ca}}$ recovered rapidly with kinetics comparable to those observed during the onset of the inhibitory effect ( $\tau \approx 200 \mathrm{~ms}$ ). A similar dose-response and time course of inhibition was found for the L-Type $\mathrm{Ca}^{2+}$ current $\left(I_{\mathrm{Ca}-\mathrm{L}}, I C_{50}\right.$ : $0.29 \pm 0.014 \mathrm{mM}, n=5-14$, Fig. $3 C, D)$. Taken together, the kinetics of $\mathrm{Ni}^{2+}$-induced $I_{\mathrm{Na} / \mathrm{Ca}}$ block were found to be limited by the time required for solution exchange. Consequently, mechanisms that require incorporation of the inhibitory compound into the cell membrane would be expected to occur with a slower time course. Furthermore, wash-out of amphiphilic compounds incorporated into the cell membrane would also be expected to occur more slowly.

\section{$\mathrm{Na}^{+}-\mathrm{Ca}^{2+}$-Exchange Current Block by Short- and Long-Chain Amphiphiles - Time Course of Inhibition And Steady-State Dose-Response RELATIONSHIP}

Because of the complexity of the potentially involved lipid signaling pathways, short- and long-chain amphiphiles with 7-, 8-, 10-and 12-carbon tails and with charged and uncharged head groups were used to explore their biophysical interactions with NCX protein (see Table 1). To assess whether amphiphiles required incorporation into the plasmalemma before exerting a blocking effect, the time course of the block and recovery of $I_{\mathrm{Na} / \mathrm{Ca}}$ were examined (Fig. 4). Because we could not directly measure the membrane incorporation and washout of the non-fluorescent amphiphiles used, we relied on the L-type $\mathrm{Ca}^{2+}$ current as a biological indicator for the interaction with the myocyte membrane. L-type $\mathrm{Ca}^{2+}$ currents were found to be sensitive to all tested amphiphiles and were recorded during depolarizations to $0 \mathrm{mV}$ (elicited at $1 \mathrm{~Hz}$ from a holding potential of $-40 \mathrm{mV}$ ).

Examples for the $I_{\mathrm{Na} / \mathrm{Ca}}$ and $I_{\mathrm{Ca}-\mathrm{L}}$ inhibition induced by $5 \mathrm{~mm}$ heptylamine and $100 \mu \mathrm{M}$ decylamine are shown in Fig. $4 A a$ and Fig. $4 A b$, respectively. Whereas heptylamine completely blocked $I_{\mathrm{Ca}-\mathrm{L}}$, it inhibited $I_{\mathrm{Na} / \mathrm{Ca}}$ by about $60 \%$ after $4 \mathrm{~s}$ of super- fusion. Recovery was noticeable for both $I_{\mathrm{Na} / \mathrm{Ca}}$ and $I_{\mathrm{Ca}-\mathrm{L}}$. Similar effects were also observed with the application of $100 \mu \mathrm{M}$ decylamine. It should be noted that recovery of the $I_{\mathrm{Na} / \mathrm{Ca}}$ current traces was incomplete because of the photoconsumption of DMnitrophen $(\approx 7 \%$ by each flash on our set-up; Egger $\&$ Niggli, 2000). This peculiarity of flash photolysis renders the analysis of the very slow time-course of recovery difficult, because it occurs in the same time window. However, the slow recovery of the $I_{\mathrm{Ca}-\mathrm{L}}$ recorded in parallel experiments suggests that both, heptylamine and decylamine, were incorporated into the cell membrane. Fig. $5 \mathrm{~A}$ shows that increasing the decylamine concentration from $1 \mu \mathrm{M}$ to $1 \mathrm{~mm}$ increased the inhibitory effect on $I_{\mathrm{Na} / \mathrm{Ca}}$ but also strongly reduced the time to reach steady-state inhibition. Representative traces for the $I_{\mathrm{Na} / \mathrm{Ca}}$ steadystate inhibition are shown in Fig. $5 \mathrm{~A}$. At a concentration of $1 \mu \mathrm{M}$, decylamine showed no effect on $I_{\mathrm{Na} / \mathrm{Ca}}$ up to $100 \mathrm{~s}$ after exposure. However, significant inhibition was found with $10 \mu \mathrm{M}$ after $20 \mathrm{~s}$ $(\approx 11 \%)$ and was about $42 \%$ after $100 \mathrm{~s}$. For concentrations of decylamine of $0.5 \mathrm{~mm}$ and $1 \mathrm{~mm}, I_{\mathrm{Na} / \mathrm{Ca}}$ was blocked by $\approx 92 \%$ after $8 \mathrm{~s}$ and by $\approx 98 \%$ after $6 \mathrm{~s}$, respectively. Depending on the concentration, a biphasic $I_{\mathrm{Na} / \mathrm{Ca}}$ block was observed (rapid component $\tau<5 \mathrm{~s}$; slow component $\tau>5 \mathrm{~s}$ ). However, the time course for the rapid $I_{\mathrm{Na} / \mathrm{Ca}}$ block $(\approx 47 \%$ after $2 \mathrm{~s}$ superfusion of $1 \mathrm{~mm}$ decylamine) was slower than the $\mathrm{Ni}^{2+}$-induced NCX block.

The time course of $I_{\mathrm{Na} / \mathrm{Ca}}$ inhibition is summarized in Table 1. Compared to the $\mathrm{C}_{7}$ amine, the time course for $I_{\mathrm{Na} / \mathrm{Ca}}$ inhibition induced by the $\mathrm{C}_{12}$ amine was three times slower. In addition, no fast component was observed. Although the non-ionic alcohols showed only modest $I_{\mathrm{Na} / \mathrm{Ca}}$ block, the $\mathrm{C}_{8}$ alcohol exhibited a faster $\tau$ for $I_{\mathrm{Na} / \mathrm{Ca}}$ inhibition than the $\mathrm{C}_{7}$ alcohol. Irrespective of the concentration used or the degree of steady-state inhibition reached, after normalization recovery from block occurred with a very similar mono-exponential time course $(\tau \approx 23 \mathrm{~s}$, Fig. 4C).

Steady-state dose-response curves of the inhibition of $I_{\mathrm{Na} / \mathrm{Ca}}$ by amphiphiles with tails of 7 and 10 carbons and with non-ionic or negatively charged head groups are shown in Fig. 5B (heptanol, heptylamine) and Fig. 5C (decanol, decylamine). At a concentration of $10 \mathrm{~mm}$, heptanol exhibited a maximal inhibition of $I_{\mathrm{Na} / \mathrm{Ca}}$ of about $33 \%$, whereas heptylamine completely blocked NCX current with the same concentration (Fig. $5 A, B$ ). In contrast to positively and negatively charged amphiphiles, which effectively blocked $I_{\mathrm{Na} / \mathrm{Ca}}$, non-ionic amphiphiles (heptanol, octanol, decanol and dodecanol) exhibited a small or even no inhibitory effect on $I_{\mathrm{Na} / \mathrm{Ca}}$ (Fig. 5B, Table 1). The efficacy of short-and longchain amines (heptylamine, octylamine, decylamine) increased with the carbon chain length (Table 1). 

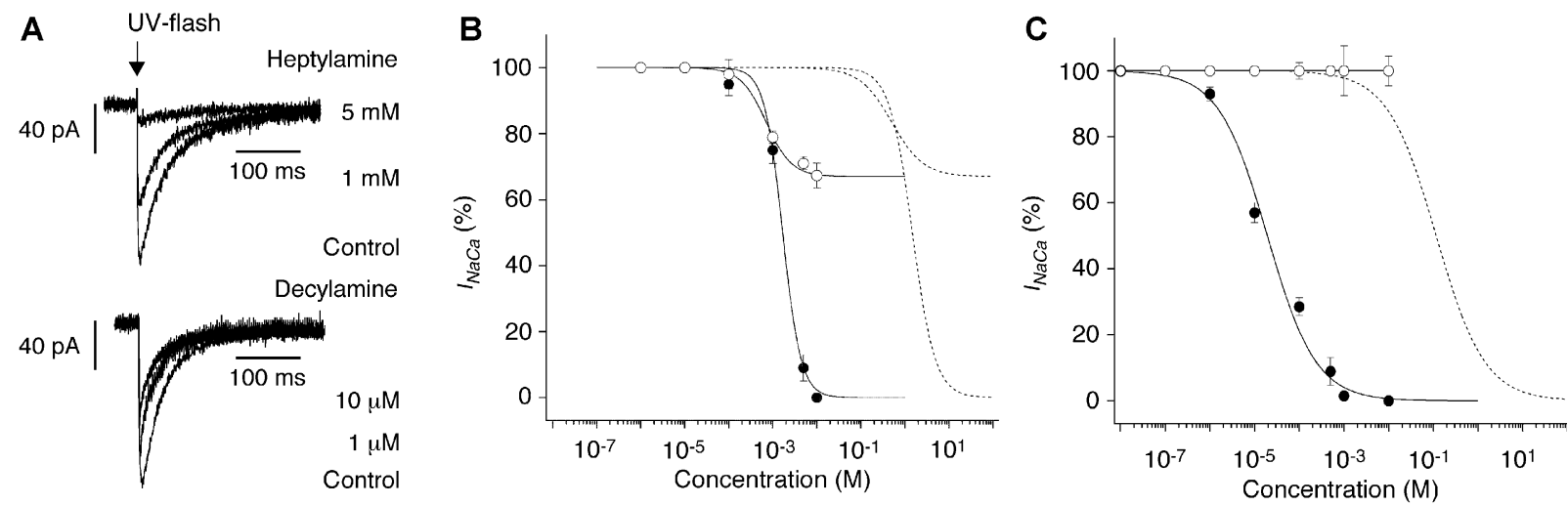

Fig. 5. Steady-state $I_{\mathrm{Na} / \mathrm{Ca}}$ inhibition induced by heptylamine and decylamine. (A) Typical examples of $I_{\mathrm{Na} / \mathrm{Ca}}$ inhibition by heptylamine $(1 \mathrm{~mm}, 5 \mathrm{~mm})$ and by decylamine $(1 \mu \mathrm{M}, 10 \mu \mathrm{M})$. Steady-state dose-response curves of the inhibition of $I_{\mathrm{Na} / \mathrm{Ca}}$ at $-40 \mathrm{mV}$ by 7carbon $(B$, heptylamine, heptanol) and 10-carbon $(C$, decylamine,

decanol) amphiphiles with alcohol $(\bigcirc)$ or amine $(\bigcirc)$ head groups. Data are given as mean \pm SEM for $n=10-11$. Amphiphile concentration corrected for the octanol/water partition coefficient are shown as dashed lines.

However, a cut-off in efficacy for the inhibition of $I_{\mathrm{Na} / \mathrm{Ca}}$ was found for the long-chain $\mathrm{C}_{12}$ amine. Dodecylamine was less potent than decylamine and inhibited $I_{\mathrm{Na} / \mathrm{Ca}}$ about $60 \%$. For the negatively charged amphiphiles tested, the short-chain oenantic acid was more potent than the long-chain lauric acid $(\approx 66 \%)$.

\section{Transbilayer Movement of Fluorescent Phospholipid Analogs}

The observed cut-off effect of the $\mathrm{C}_{12}$ amphiphiles could suggest that the transbilayer movement ("flip") of the amphiphiles is an important step before they can exert their blocking effects on NCX from the inner leaflet of the membrane. This hypothesis was examined in another series of experiments using the phospholipid analogs NBD-C 6 - $\mathrm{HPC}$ and NBD-C ${ }_{12}^{-}$ HPC. Like other short-chain amphiphiles NBD-C $6^{-}$ HPC could penetrate the membrane much faster than the longer NBD-C12-HPC, even if both also have a C16 moiety, and thus could affect NCX from the cytosolic side of the membrane. Here we used the fluorescence increase in intracellularly located membranes after $60 \mathrm{~min}$ at $37^{\circ} \mathrm{C}$ as an indicator for the transbilayer movement of the fluorescent phospholipid analogs. In the experiment shown in Fig. $6 A$ the cells were exposed to $50 \mu \mathrm{M}$ NBD-C 6 -HPC or NBD-C ${ }_{12}-\mathrm{HPC}$, respectively. In contrast to NBD-C $\mathrm{C}_{6}$-HPC-treated myocytes (Fig. 6Aa), where the whole cytoplasm showed fluorescence, in NBD- $\mathrm{C}_{12}$-HPC-treated cells the fluorescence preferentially remained in the plasmalemma (Fig. 6Ab). We hypothesized that the $\mathrm{C}_{6}$ dye could exert its inhibitory effect on NCX from the inner leaflet of the membrane, because it has a higher ability for transbilayer movement compared to the $\mathrm{C}_{12}$ dye. To test this hypothesis, we introduced $10 \mu \mathrm{m}$ NBD-C 6 -HPC or NBD-C 12 -HPC in the pipette solution. Both phospholipid analogs have the tendency to accumulate in the cell around the region near the tip of the pipette, presumably by binding to organellar membranes. For that reason we loaded the cell with the fluorescent analogs by moderate pressure injection in the whole-cell configuration of the patch-clamp technique. After 2-3 min of loading, both dyes significantly blocked the $I_{\mathrm{Na} / \mathrm{Ca}}$ (Fig. 6Ba). Representative traces are given in Fig. $6 B a$ and the experimental series is summarized in Fig. 6Bb. Interestingly, NBD$\mathrm{C}_{12}$-HPC inhibited $I_{\mathrm{Na} / \mathrm{Ca}}$ to about $90 \%$, whereas the NBD-C 6 -HPC-induced $I_{\mathrm{Na} / \mathrm{Ca}}$ block was only about $57 \%$. Thus, the potency of the two dyes was opposite when applied intracellularly. This discrepancy in potency can be explained by the observed differences in transbilayer movement properties of both dyes when applied extracellularly.

\section{Molecular Mechanisms of NCX Block}

Among the amphiphiles tested in this study, longchain amines $\left(\mathrm{C}_{10}\right)$ were found to be the most powerful blocking lipids. For this reason, we decided to examine the mechanisms of block by decylamine in more detail. In principle, $I_{\mathrm{Na} / \mathrm{Ca}}$ can be blocked pharmacologically by interfering with different molecular mechanisms. A blocker could either completely immobilize a certain fraction of the exchange proteins, or the inhibitor could interfere with one partial reaction step of the exchange cycle, essentially slowing down the turnover of individual molecules. In the first case the remaining unblocked exchanger molecules would be expected to exhibit a normal exchange cycle, while in the latter case rate-limiting partial reactions could change, possibly leading to an alteration of the voltage-dependence (Hilgemann, Feng \& Nasuhoglu 1991, Niggli \& Lipp, 1994). In order to determine the voltage dependence of the $\mathrm{Na}^{+}-\mathrm{Ca}^{2+}$ exchanger, we analyzed peak $I_{\mathrm{Na} / \mathrm{Ca}}$ elicited by flash photolytic $\left[\mathrm{Ca}^{2+}\right]_{i}$ jumps performed in 
the voltage range from $-80 \mathrm{mV}$ to $+20 \mathrm{mV}$ before and during a $50 \%$ block of $I_{\mathrm{Na} / \mathrm{Ca}}$ induced by $20 \mu \mathrm{M}$ decylamine (Fig. 7A). Although NCX activity was clearly reduced by decylamine, the peak $I_{\mathrm{Na} / \mathrm{Ca}}$ had a tendency to be larger at more negative potentials, irrespective of the decylamine block. After normalization, the $I_{\mathrm{Na} / \mathrm{Ca}}-V$ curves measured during application of $20 \mu \mathrm{M}$ decylamine could be superimposed on the control data (Fig. 7B), confirming that the currentvoltage relationship was not affected by the interaction of the amphiphile with the exchanger $(82 \mathrm{mV} v s$. $97 \mathrm{mV}$ for an e-fold change before and during block, respectively). We also calculated the charge transport mediated by NCX from the integral of the $I_{\mathrm{Na} / \mathrm{Ca}}$ under control conditions and under $50 \%$ block of its function induced by $20 \mu \mathrm{M}$ decylamine (Fig. $7 \mathrm{C}$ ). One example is given in Fig. $7 C$. It was a pre-condition for all these experiments that the intracellular $\mathrm{Ca}^{2+}$ concentration jumps induced by flash photolysis of caged $\mathrm{Ca}^{2+}$ were of comparable amplitude, in other words there were comparable substrate concentrations accessible for the NCX under all conditions. In addition, for analysis of the charge transport, $I_{\mathrm{Na} / \mathrm{Ca}}$ has also to be normalized to the membrane capacitance. From this analysis it became clear that the $I_{\mathrm{Na}}$ $\mathrm{Ca}$ block by decylamine slowed the time course but did not significantly reduce the magnitude of NCX net charge transport (Fig. 7D).

Additional mechanistic information about the NCX block can be obtained under NCX $\mathrm{Ca}^{2+}$-influx mode conditions. However, there is a possibility that depending on their charge, amphiphiles could block the inward currents but stimulate the outward currents. This could also explain differing observations in vesicle preparations or in giant-patch experiments, where negative amphiphiles tend to stimulate exchange activity (Philipson, 1984; Vemuri \& Philipson, 1988; Hilgemann \& Collins, 1992). Here we used the $\mathrm{Ca}^{2+}$-influx via the exchanger as a direct measure for the NCX activity working under outward current conditions. The NCX Ca ${ }^{2+}$-influx mode was activated by a depolarization step from $-40 \mathrm{mV}$ to $+60 \mathrm{mV}$ for $2 \mathrm{~s}$ in the presence of $10 \mu \mathrm{M}$ nifedipine (Fig. $8 \mathrm{~A}$ ), while the fluorescence change was detected with the $\mathrm{Ca}^{2+}$ indicator fluo-3. The resulting $\mathrm{Ca}^{2+}$ transient was completely blocked by $8 \mathrm{mM} \mathrm{Ni}^{2+}$, indicating that it was exclusively driven by the NCX and was used for normalization. In the presence of the positively charged decylamine ( $2 \mathrm{~min}, 20 \mu \mathrm{M})$ as well as with the negatively charged amphiphile caprinic acid (2 min, $500 \mu \mathrm{M})$ the NCX-mediated $\mathrm{Ca}^{2+}$ influx was reduced by $\approx 44 \%$ and by $\approx 54 \%$, respectively (Fig. $8 B$ ).

\section{Discussion}

It has been suggested that changes in the lipid composition of cardiac muscle cell membranes are causally related to the development of arrhythmias and the extent of ischemic damage (Corr \& Cain, 1979). As a major mechanism by which lipids generate these effects, alterations of the movement of $\mathrm{Ca}^{2+}$ through $\mathrm{Ca}^{2+}$ channels, NCX and $\mathrm{Ca}^{2+}$ transporters have been proposed. Several lines of evidence indicate that the cardiac $\mathrm{Na}^{+}-\mathrm{Ca}^{2+}$ exchange activity (e.g., $I_{\mathrm{Na} / \mathrm{Ca}}$ ) could be affected by changes of the lipid membrane environment (Vemuri \& Philipson, 1988; Hale et al., 1988; Luciani et al., 1991; Hilgemann \& Collins, 1992, Collins \& Hilgemann, 1993). We hypothesized that blocking or stimulating effects of lipids on the NCX may be mediated by biophysical interactions with the NCX molecule from the inner leaflet of the membrane (see Fig. 1C). To test this hypothesis, NCX currents were elicited in a highly specific manner by photorelease of "caged" $\mathrm{Ca}^{2+}$ (Niggli \& Lederer, 1993) in combination with fluorescent phospholipid analogs and various aliphatic amphiphiles as potential modulators of the NCX activity.

In principle, amphiphiles could directly and rapidly alter the properties of the protein without prior incorporation into the cell membrane. For all other possible mechanisms of interaction, including local changes in electrical charges around the protein (e.g., by $\mathrm{Ca}^{2+}$ or $\mathrm{Na}^{+}$), such an incorporation is required. Similarly, for an electrostatic interaction of the head group with the tansmembrane domain of the protein, incorporation is a prerequisite. Moreover, all these mechanisms involving prior membrane incorporation of the lipid can also occur at the inner leaflet of the bilayer after a transbilayer flip catalyzed by a lipid translocase (or flippase). Some of these mechanisms are known to be important for lipid interactions with other transmembrane proteins, for example for the interaction between acylcarnitine and $\mathrm{K}^{+}$channels (Lamers et al., 1994).

\section{DiRECT INTERACTION}

One example of direct block of NCX is exemplified by the $\mathrm{Ni}^{2+}$ application. It is assumed that the $\mathrm{Ni}^{2+}$ block of the exchanger is immediate and only limited

Fig. 6. $I_{\mathrm{Na} / \mathrm{Ca}}$ block induced by interaction from the inner membrane leaflet by NBD-C 6 -HPC or NBD-C 12 -HPC uptake. $(A)$ Confocal image of a single ventricular myocyte incubated with $50 \mu \mathrm{M}$ of the fluorescent lipid probe NBD-C ${ }_{6}$-HPC $(A a)$ or NBD$\mathrm{C}_{12}$-HPC $(A b)$ for $60 \mathrm{~min}$ at $37^{\circ} \mathrm{C}$ (left) and the corresponding surface plots of a region of interest (white rectangle) (right). (Ba) Traces show, from top to bottom, $I_{\mathrm{Na} / \mathrm{Ca}}$ elicited at $-40 \mathrm{mV}$ normalized to the membrane capacitance in myocytes under control conditions, with $5 \mu \mathrm{M}$ NBD-C 6 -HPC and NBD-C 12 -HPC-containing pipette solution, respectively. ( $B b I_{\mathrm{Na} / \mathrm{Ca}}$ block induced with

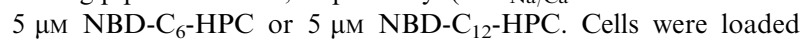
with the fluorescent analogs by moderate pressure injection in the whole-cell configuration of the patch-clamp technique (error bars represent mean \pm SEM., $\left.n=4,{ }^{*} P<0.05,{ }^{*} P<0.1\right)$. 
A NBD-C $_{6}$

a

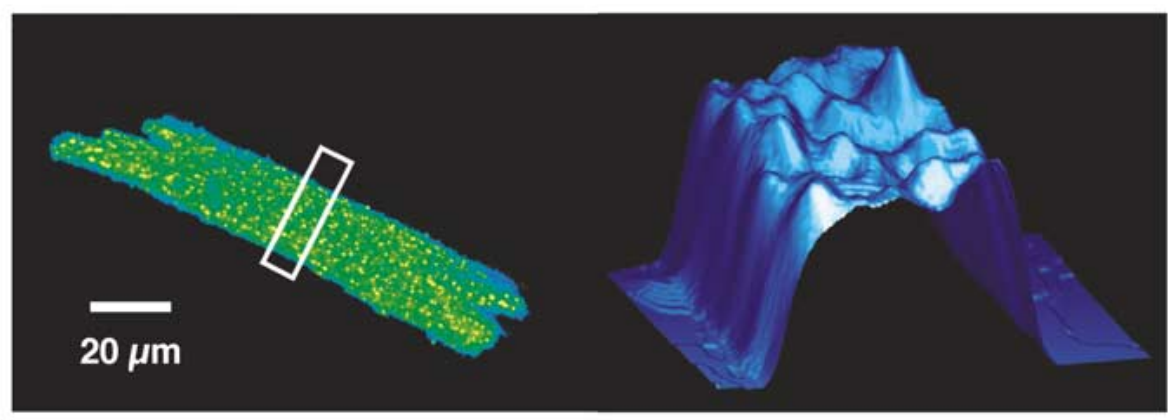

NBD-C 12

b

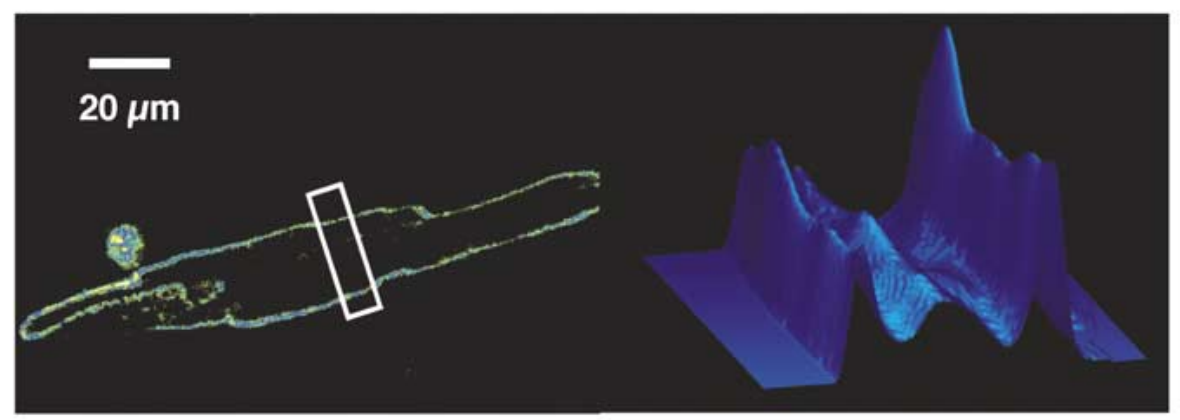

B a

b

Control $\downarrow$ uv-flash

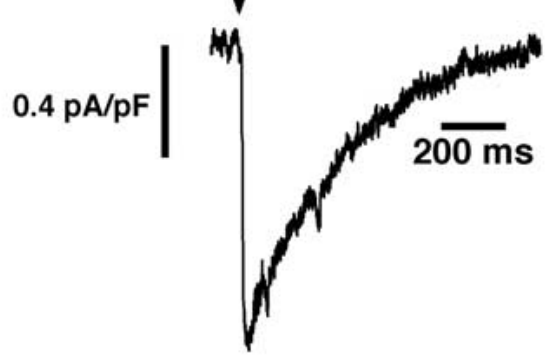

NBD-C $6 \downarrow$ Uv-flash

$0.4 \mathrm{pA} / \mathrm{pF} / 20$

NBD-C $12 \downarrow$ UV-flash

$0.4 \mathrm{pA} / \mathrm{pF}$

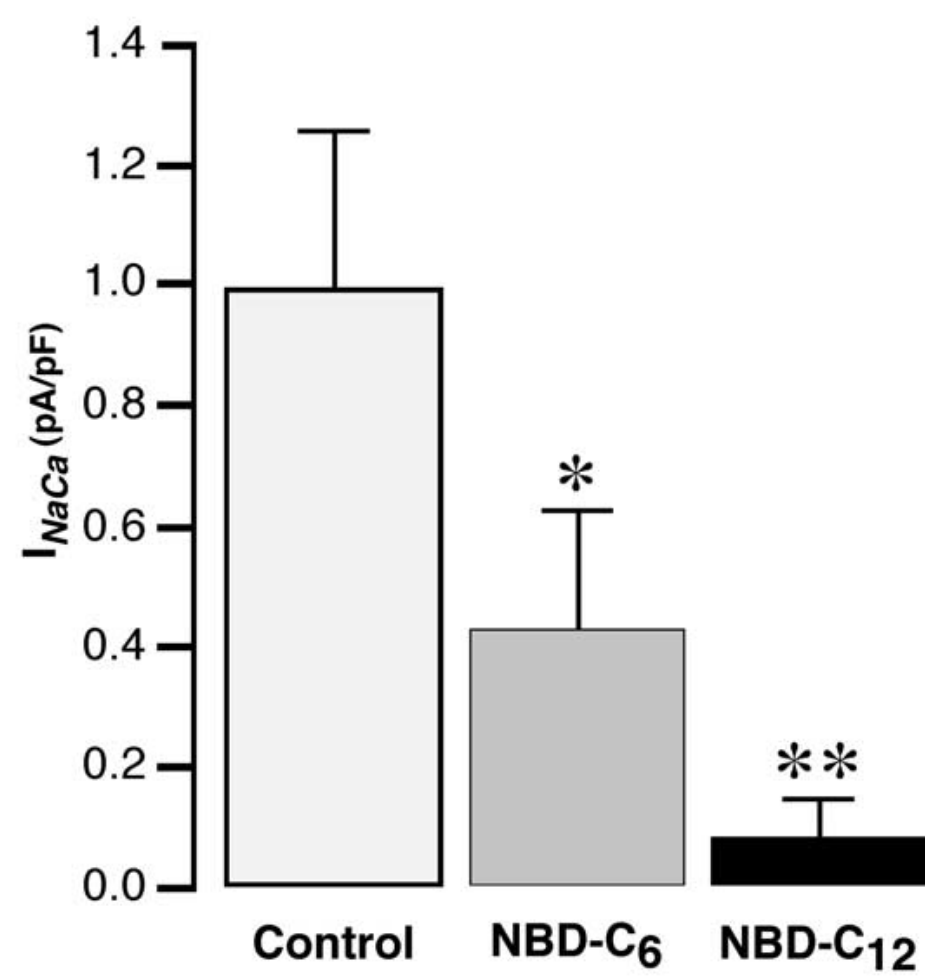



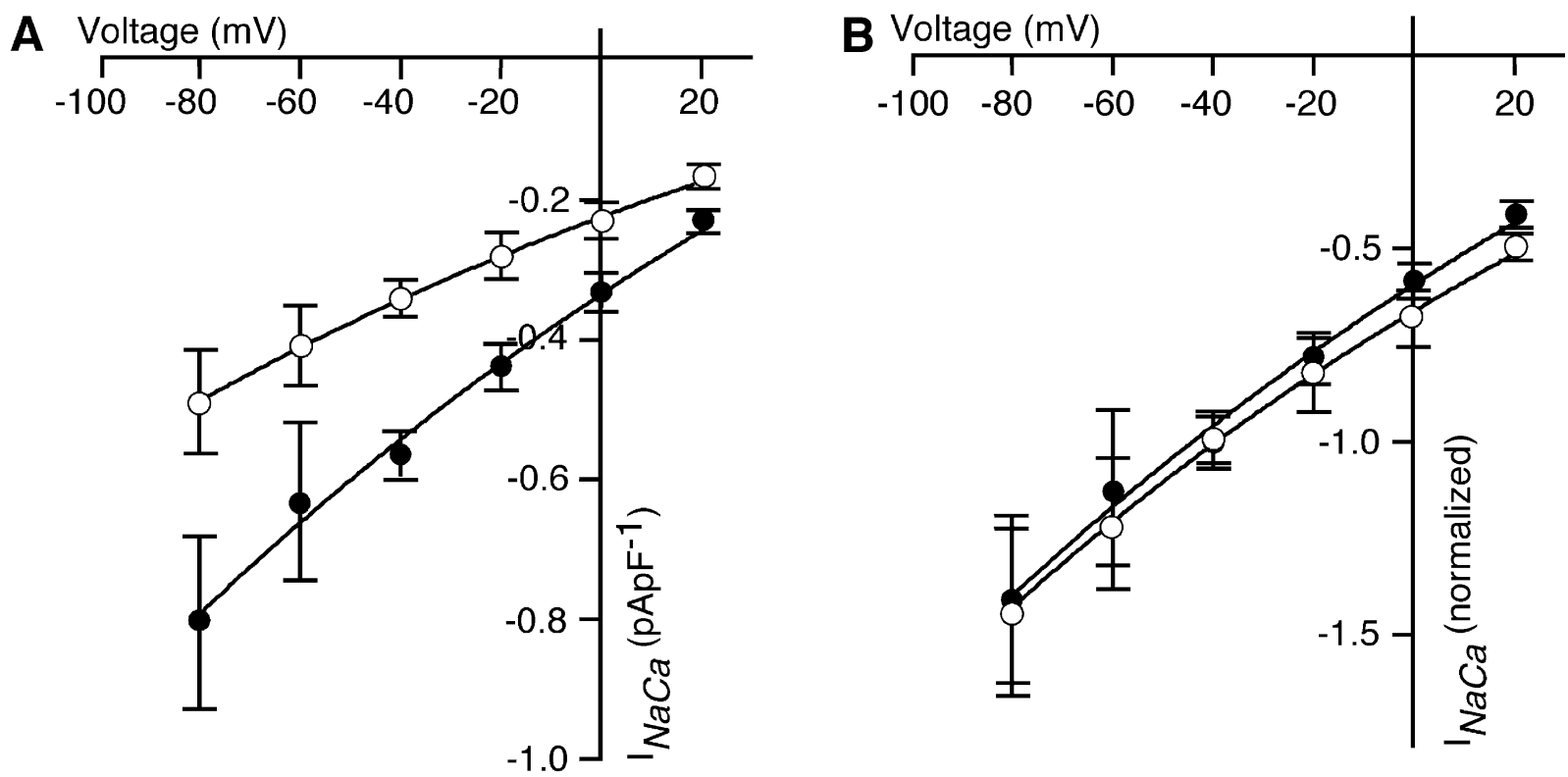

C
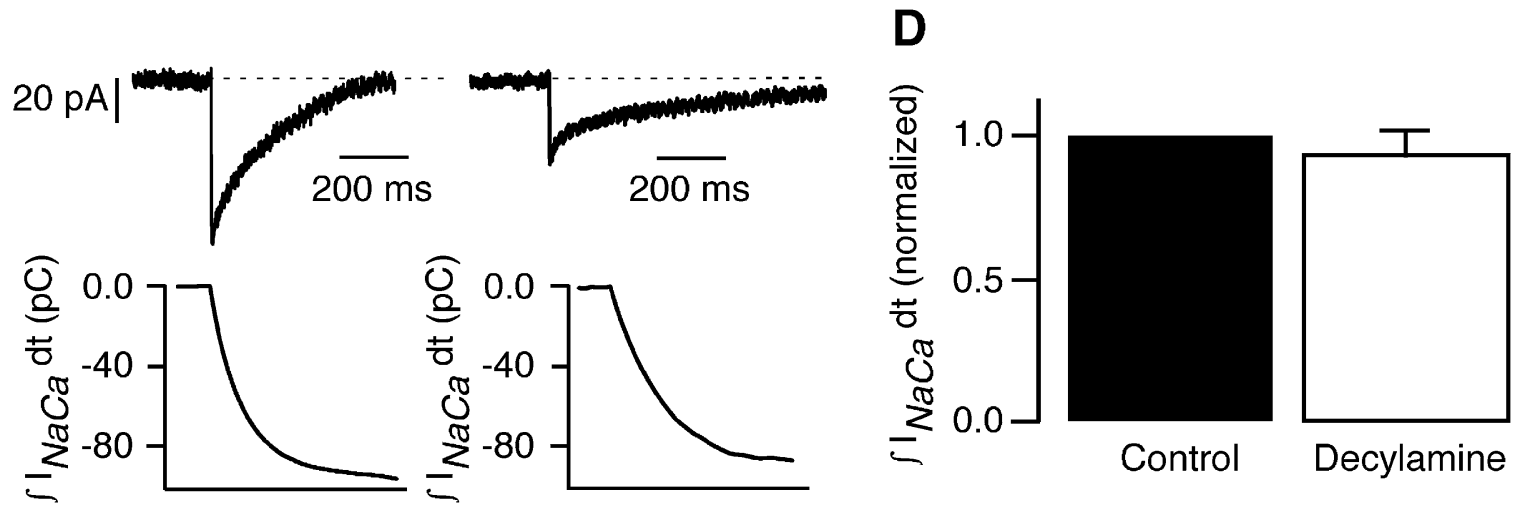

Fig. 7. Voltage dependence of the net charge transport is not affected by decylamine. (A) Voltage-dependence of $I_{\mathrm{Na} / \mathrm{Ca}}$ shown as peak $I_{\mathrm{Na} / \mathrm{Ca}}$ current density and $(B)$ voltage dependence of $I_{\mathrm{Na} / \mathrm{Ca}}$ normalized to the peak $I_{\mathrm{Na} / \mathrm{Ca}}$ elicited at $-40 \mathrm{mV}$ in myocytes under control conditions $(\mathbf{O})$ and after $20 \mu \mathrm{M}$ decylamine treatment $(\bigcirc)$. The experimental data were fitted with a monoexponential func-

by the rate of delivery by the superfusion system (Egger et al., 1999). Indeed, under our experimental conditions this appears to be the case within the time resolution of our measurements. The comparison of the time course of $I_{\mathrm{Na} / \mathrm{Ca}}$ block mediated by $\mathrm{Ni}^{2+}$ with the time course of block induced by amphiphiles allowed us to distinguish between blocking effects mediated by direct binding on the exchanger protein and those requiring prior incorporation into the membrane. This is true under the assumption that incorporation of amphiphiles is slow compared to "on" rate of amphiphile binding.

\section{INCORPORATION}

Since for all amphiphiles used in this study, the time constant of $I_{\mathrm{Na} / \mathrm{Ca}}$ inhibition was found to be significantly longer than for the $\mathrm{Ni}^{2+}$-induced $I_{\mathrm{Na} / \mathrm{Ca}}$ tion. (C) The transported charge $\left(\int I_{\mathrm{Na} / \mathrm{Ca}} \mathrm{d} t\right)$ under control conditions (left) and after $20 \mu \mathrm{m}$ decylamine treatment (right) and $(D)$ normalized charge transport (integral of $I_{\mathrm{Na} / \mathrm{Ca}}$ current densities $[\mathrm{pA} / \mathrm{pF}]$ for control cells $=1$ ) mediated by the NCX (error bars represent mean \pm SEM, $n=4$ ).

block, we conclude that the slow $I_{\mathrm{Na} / \mathrm{Ca}}$ block requires incorporation of the amphiphiles into the membrane. Several additional observations support this hypothesis: We noticed that the $I_{\mathrm{Na} / \mathrm{Ca}}$ recovery appeared to be much slower than the time course of inhibition. In parallel, the time constant of the NCX inhibition became smaller when the concentration was elevated. According to this, the slower time course observed with low concentrations could be due to the time necessary to attain a sufficiently high amphiphile concentration in the plasmalemma. Depending on their structure and on the composition of the membrane, not all amphiphiles incorporate identically and their final concentration reached within the membrane strongly depends on their hydrophobicity. This has been demonstrated for short-chain aliphatic alcohols, where the hydrophobicity and membrane integration directly correlate with the octanol/water 
partition coefficient (McKarns et al., 1997) and allows an approximate comparison of amphiphiles with different chain lengths. Two examples are given in Fig. 5B and Fig. 5C (dotted lines) where the doseresponse curves are accordingly shifted to the right, indicating that, e.g., decylamine, where the shift is greater, incorporates more easily than heptylamine. This could account for the greater effect of decylamine on $I_{\mathrm{Na} / \mathrm{Ca}}$ as well as on $I_{\mathrm{Ca}-\mathrm{L}}$. Confocal microscope experiments with fluorescent phospholipid analogs showed that the $I_{\mathrm{Na} / \mathrm{Ca}}$ inhibition correlates with the incorporation of the dye into the sarcolemma (Fig. 2A). However, it can be assumed that the $I_{\mathrm{Na} / \mathrm{Ca}}$ lock is not a linear function of the amphiphile concentration, therefore we do not expect a perfect correlation between the fluorescence increase and the current decrease. Taken together, our results suggest that the $I_{\mathrm{Na} / \mathrm{Ca}}$ inhibition mediated by longand short-chain amphiphiles requires incorporation into the plasmalemma. However, this step alone cannot explain all features of NCX inhibition induced by amphiphiles observed in this study.

\section{HeAd-Group EfFects}

When comparing the potency and efficacy of different amphiphiles, it turned out that the structure or the charge of the head group were important determinants for the block of $I_{\mathrm{Na} / \mathrm{Ca}}$. At a $\mathrm{pH}$ of 7.4, amine head groups are positively charged $(+1)$, whereas alcohols are neutral. On amphiphiles of identical chain length the cationically charged amine head group was more potent than the anionically charged group or the uncharged alcohol head group. This suggests that the electrical charge of the head group could be a determinant for the blocking effect on NCX. The differential block of $I_{\mathrm{Na} / \mathrm{Ca}}$ by amphiphiles with dissimilar head-group charge is in agreement with results obtained in cardiac sarcolemmal vesicles (Philipson et al., 1984) and in rat cardiac muscle cells (Haworth, Goknur \& Berkaff, 1989). In contrast to findings in cardiac sarcolemmal vesicles (Philipson et al., 1984), stimulation of NCX inward current due to application of negatively charged amphiphiles was not observed. This may be because of the two very different functional tests of NCX activity applied in both studies, which makes it difficult to compare the observations directly (see also Discussion below).

\section{Aliphatic Chain-Length Effects}

Nevertheless, based on our data we cannot exclude that structural features of the head group other than the charge are also important. In addition to differences observed with specific head groups, our results suggest that the number of carbon atoms of the aliphatic chain is important for the mechanism of block of the net charge transport. The efficacy of positively charged amphiphiles for inhibition of $I_{\mathrm{Na} / \mathrm{Ca}}$ appears to increase with the carbon-chain lengths. This can be explained, at least partly, by the correlation of the hydrophobicity of these short/long-chain amphiphiles $\left(\mathrm{C}_{7}\right.$ to $\left.\mathrm{C}_{10}\right)$ and their ability to alter physico-chemical membrane properties. Interestingly, a cut-off of this correlation was found with $\mathrm{C}_{12}$ amines. Moreover, non-ionic amphiphiles (alcohols) with long hydrocarbon chains were found to be inefficient as $I_{\mathrm{Na} / \mathrm{Ca}}$ blockers. For amphiphiles with comparable hydrophobic characteristics similar non-specific "membrane detergent effects" on the NCX might be expected. However, this is not the case and amphiphiles with comparable chain length induce graded effects on NCX function, which vary from complete block to no-response. This tends to support the idea that amphiphiles directly affect NCX molecules and makes indirect interactions by amphiphiles unlikely, particularly "detergent" effects or effects on the membrane fluidity, which may also be able to affect NCX function and results.

\section{Transbilayer Movement}

Short-chain alcohols are relatively small molecules consisting of a polar, hydrophilic hydroxyl group and a nonpolar, hydrophobic hydrocarbon chain that has a high affinity for biological membranes. The transbilayer movement of these short-chain alcohols is expected to be faster than charged amphiphiles (e.g., amines). However, the extent to which efficient NCX block occurs probably depends on the readiness with which the amphiphiles penetrate the membrane. This view is supported by our experiments using the fluorescent phospholipid analogs $\mathrm{NBD}-\mathrm{C}_{6}-\mathrm{HPC}$ and NBD- $\mathrm{C}_{12}$-HPC, where the $\mathrm{C}_{6}$ analog was found to have a higher efficacy to block $I_{\mathrm{Na} / \mathrm{Ca}}$ than the $\mathrm{C}_{12}$ analog, when both were applied from the extracellular side. Surprisingly, this behavior was reversed when the dye was delivered to the cell interior via the patch pipette. In these experiments, the $\mathrm{C}_{12}$ analog was the more potent NCX blocker. The more efficient NCX block by the $\mathrm{C}_{6}$ analog applied extracellularly could be due to its faster transbilayer movement. On the contrary, the higher efficacy for NCX inhibition induced by the $\mathrm{C}_{12}$ analog when delivered from the cytoplasmic side, could be due to its higher hydrophobicity. Thus, interactions at the inner leaflet of the membrane appear to be responsible for the blocking effect on NCX function. These observations suggest that membrane incorporation of the amphiphiles and their ability to undergo transmembrane movement are important determinants for interaction with NCX and for high efficacy of $I_{\mathrm{Na} / \mathrm{Ca}}$ inhibition.

A central observation was that, depending on the structure, charge and concentration of the amphiphiles, $I_{\mathrm{Na} / \mathrm{Ca}}$ was inhibited (Fig. 4, Table 1). In principle, a decrease in total $I_{\mathrm{Na} / \mathrm{Ca}}$ could result from 


\section{A}

$+60 \mathrm{mV}$

$-40 \mathrm{mV}$
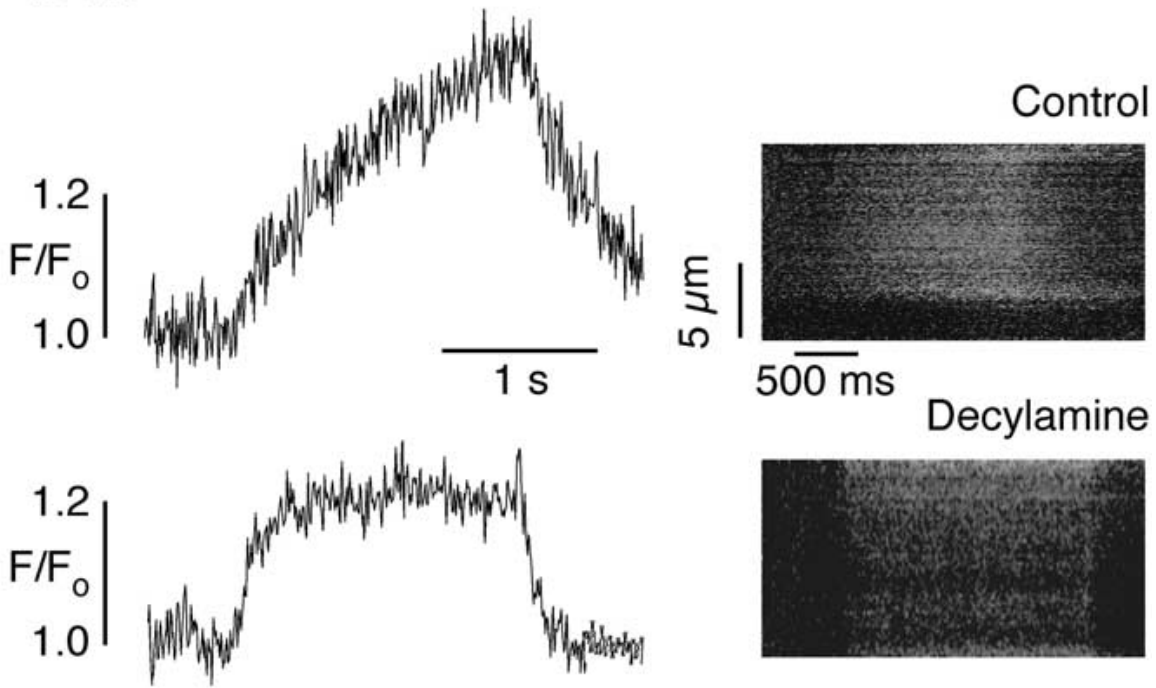

Decylamine

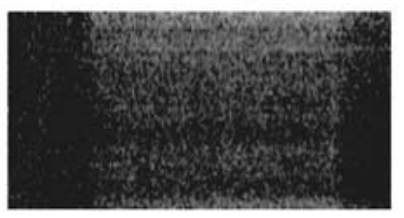

Caprinic acid
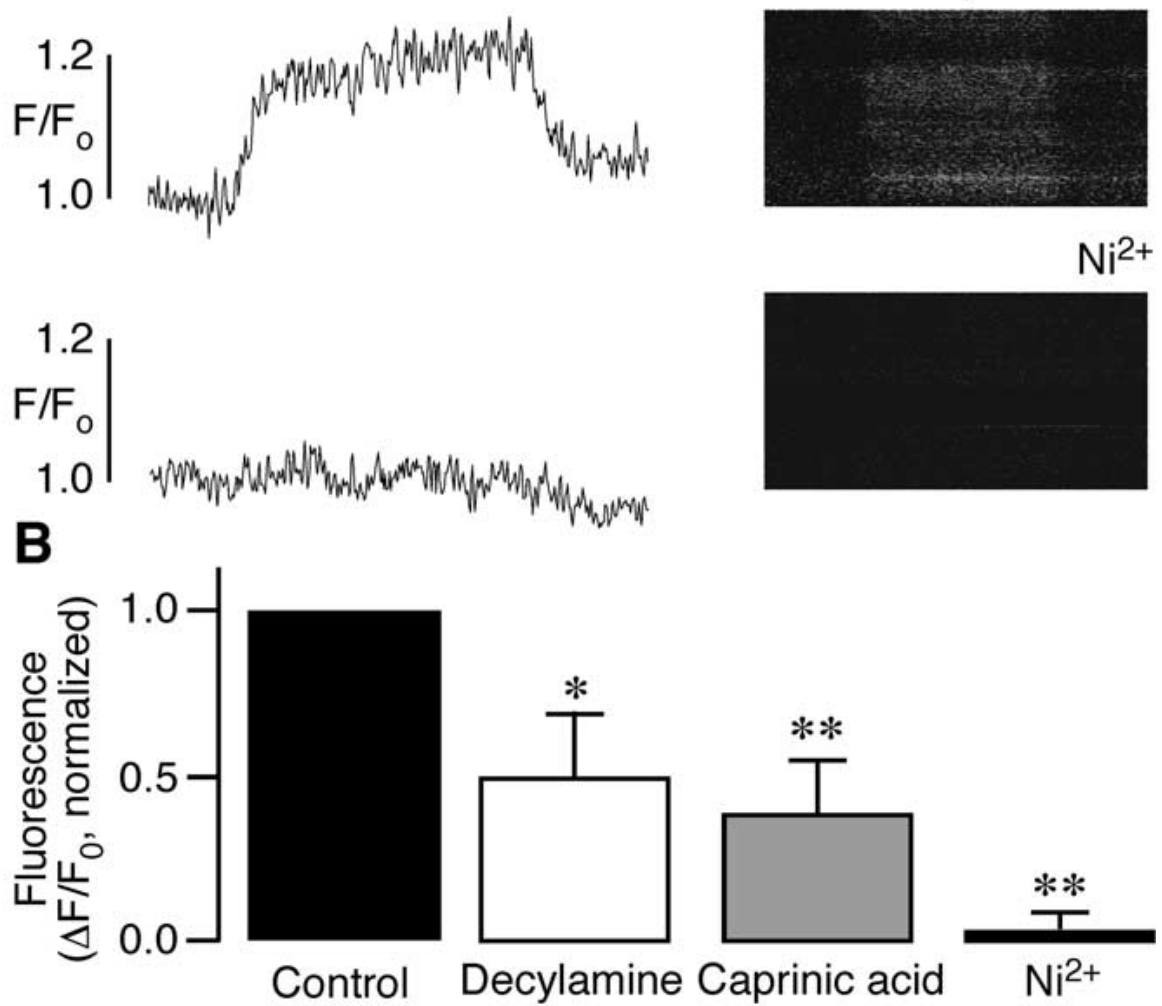

Fig. 8. $\mathrm{Ca}^{2+}$ influx mode of the NCX. (A) Applied voltage protocol and below, typical examples of NCX-mediated $\mathrm{Ca}^{2+}$ influx measured as fluo-3 fluorescence change and the corresponding line-scan images (at right), in the presence of $10 \mu \mathrm{m}$ nifedipine. $\mathrm{NCX} \mathrm{Ca}^{2+}$. influx mode was elicited by a voltage step to $+60 \mathrm{mV}$ (from a holding potential of $-40 \mathrm{mV}, 2 \mathrm{~s}$ duration). Decylamine ( $20 \mu \mathrm{M})$ and caprinic acid $(500 \mu \mathrm{M})$ were applied for $2 \mathrm{~min}$, an $8 \mathrm{~mm} \mathrm{Ni}^{2+}$ puff of 1-3 s duration was applied to block the NCX. (B) Fluo-3 fluorescence change normalized to the $\mathrm{Ni}^{2+}$ difference $(8 \mathrm{mM})$. (error bars represent mean $\left.\pm \operatorname{sEM}, n=3-6,{ }^{* *} P<0.05,{ }^{*} P<0.1\right)$. 
(1) a reduced number of active NCX molecules, (2) a lower turnover rate of the ion exchange mechanism or (3) an altered stoichiometry or electrogenicity of the $\mathrm{Na}^{+}-\mathrm{Ca}^{2+}$ exchange. Since the voltage-dependence of NCX is believed to be intimately linked to the rate-limiting membrane-crossing partial reaction of the exchange cycle, any modification of a specific partial reaction influencing the rate-limiting step would be expected to result in a change of the overall voltage-dependence of transport and $I_{\mathrm{Na} / \mathrm{Ca}}$ (Hilgemann, Nicoll \& Philipson, 1991, Rakowski, 1993). However, modifications of very rapid partial reactions, such as ion binding, may not result in detectable changes of the voltage dependence. Although $18 \mu \mathrm{M}$ decylamine inhibited NXC activity by $50 \%$, the voltage dependence of $I_{\mathrm{Na} / \mathrm{Ca}}$ remained virtually unchanged (Fig. 7B). Since the amount of photo-released $\mathrm{Ca}^{2+}$ does not vary significantly from flash to flash, the net charge transported during $I_{\mathrm{Na} / \mathrm{Ca}}$ should remain unchanged, even if the turn over rate of the exchange cycle was slowed down. The net charge transport can be estimated by numerical integration of the $I_{\mathrm{Na} / \mathrm{Ca}}$ (Fig. $7 C$ ). Although this is not very reliable under conditions where $I_{\mathrm{Na} / \mathrm{Ca}}$ is small, this analysis suggested that NCX net charge transport was not significantly affected by decylamine (Fig.7D). We have also shown that the $\mathrm{Ca}^{2+}$-influx mode was not affected differently than the $\mathrm{Ca}^{2+}$-efflux mode under conditions where the net charge was blocked by about $50 \%$. For all positively as well as negatively charged amphiphiles tested, the $\mathrm{Ca}^{2+}$-inward mode as well as the NCX-outward mode were both blocked in a quantitatively comparable fashion $\left(I_{\mathrm{Na} / \mathrm{Ca}} 50 \%\right.$ block versus $\mathrm{Ca}^{2+}$ influx block $44-54 \%$, respectively; Fig. 8). All three findings, the unchanged net charge transport, the block of the $\mathrm{Ca}^{2+}$-influx accordingly to the block of net charge transport, as well as the unaltered $I-V$ relationship of $I_{\mathrm{Na} / \mathrm{Ca}}$ suggest that a reduced number of active NCX molecules (or a reduced turnover rate) rather than a change in stoichiometry are responsible for reduction of $I_{\mathrm{Na} / \mathrm{Ca}}$.

\section{RELEVANCE}

The inhibitory effect of amphiphiles increased in parallel with the length of the aliphatic chain ranging between $C_{7}$ to $C_{10}$ and was more potent with an amine head group than with an alcohol. The cut-off in NCX inhibition by the long-chain cationic amphiphile $\left(\mathrm{C}_{12}\right)$, the analysis of the time course of NCX block and comparison with the $\mathrm{Ni}^{2+}$-induced NCX inhibition suggest that amphiphiles need to be incorporated into the plasmalemma followed by transbilayer movement to the inner membrane leaflet to effectively block the NCX. However, it remains open whether the effect is related to interactions of the amphiphiles with a hydrophobic domain of NCX or with other associated proteins. This conclusion is supported by confocal experiments showing the correlation between time course of incorporation of fluorescent phospholipid analogs and $I_{\mathrm{Na} / \mathrm{Ca}}$ inhibition.

Interestingly, chain length-dependent differences in their efficacy to block NCX function were reversed when the dye was directly applied intracellularly, again supporting the flip hypothesis mentioned above. So far we are not yet able to identify the precise molecular interaction occurring in the inner leaflet of the membrane. But we favor the view that both, hydrophobic and electrostatic interactions, are important factors for NCX modulation and/or regulation by amphiphiles. We also speculate from our experiments and from other studies that similar mechanisms are most likely important during alterations of the NCX in ischemia and reperfusion, where the lipid environment is perturbed (Corr et al., 1979; Vemuri \& Philipson, 1988; Hale et al., 1998; Collins \& Hilegemann, 1993; Luciani et al., 1991). However, the exact role of NCX in cardiac ischemia remains unclear and contradictory results (e.g., Hampton et al., 2000; Elias et al., 2001) may depend on the animal model and the functional test for NCX activity. It has been observed on sarcolemmal vesicles (Philipson et al., 1984) that LPC decreased $I_{\mathrm{Na} / \mathrm{Ca}}$, whereas LPA increased it. Effects of LPA and LPC on $I_{\mathrm{Na} / \mathrm{Ca}}$ reported in our study can be due to changes of $\mathrm{Ca}^{2+}$ release from the SR and participation of intracellular signaling pathways (e.g., PKC-dependent and tyrosine kinase-dependent pathways (Watson \& Gold, 1997). They can also change the charges of phospholipids around the protein and then shift activation and inactivation parameters, as observed with L-palmitylcarnitine (Inoue \& Pappano, 1983). During cardiac ischemia numerous lipases are activated, leading to the formation of arachidonic acid and PIP $_{2}$ (Hilgemann et al., 2001) and, at the same time, lysophosphoglycerides and lysophosphatidylcholine concentrations are increased due to a less efficient lipid catabolism (see Carmeliet, 1999). Additional studies will be needed to determine how and to what extent NCX is altered by these changes of its lipid environment during cardiac ischemia.

This work was supported by the Swiss National Science Foundation (68056.02 to M.E. and 61344.00 to E.N.), by the Roche Research Foundation to M.E. and the Swiss Cardiovascular Research \& Training Network. We thank D. Lüthi for excellent technical assistance.

\section{References}

Bergmann, S.R., Ferguson, T.B., Sobel, B.E. 1981. Effects of amphiphiles on erythrocytes, coronary arteries, and perfused hearts. Am. J. Physiol. 240:H229-H237 
Bers, D.M. 2001. Excitation-Contraction Coupling and Cardiac Contractile Force. Kluwer Academic, Dortrecht, Boston, London

Bersohn, M.M., Philipson, K.D., Weiss, R.S. 1991. Lysophosphatidylcholine and sodium-calcium exchange in cardiac sarcolemma: comparison with ischemia. Am. J. Physiol. 29:C433-C438

Blatter, L.A., Niggli, E. 1998. Confocal near-membrane detection of calcium in cardiac myocytes. Cell Calcium 23:269-279

Bridge, J.H.B., Smolley, J.R., Spitzer, K.W. 1990. The relationship between charge movements associated with $\mathrm{I}_{\mathrm{Ca}}$ and $\mathrm{I}_{\mathrm{Na}-\mathrm{Ca}}$ in cardiac myocytes. Science 248:376-378

Carmeliet, E. 1999. Cardiac ionic currents and acute ischemia: from channels to arrhythmias. Physiol. Rev. 79:917-1017

Collins, A., Hilgemann, D.W. 1993. A novel method for direct application of phospholipids to giant excised membrane patches in the study of sodium-calcium exchange and sodium channels currents. Pfluegers Arch. 423:347-355

Corr, P.B., Cain, M.E. 1979. Potential arrhythmogenic electrophysiological derangements induced by lysophosphoglycerides. Circ. Res. 44:822-832

Crespo, L.M., Grantham, C.J., Cannell, M.B. 1990. Kinetics, stoichiometry and role of the Na-Ca exchange mechanism in isolated cardiac myocytes. Nature. 345:618-621

Egger, M., Niggli, E. 1999a. Regulatory function of Na-Ca exchange in the heart: milestones and outlook. J. Membrane Biol. 168: $107-130$

Egger, M., Niggli, E. 1999b. Modulation of the $\mathrm{Na}^{+} / \mathrm{Ca}^{2+}$ exchanger in cardiac myocytes: Interactions with amphiphiles. Biophys. J. 76:A462.

Egger, M., Niggli, E. 2000. Paradoxical block of the $\mathrm{Na}^{+}-\mathrm{Ca}^{2+}$ exchanger by extracellular protons in guinea-pig ventricular myocytes. J. Physiol. 523:353-366

Egger, M., Ruknudin, A., Niggli, E., Lederer, W.J., Schulze, D.H. 1999. $\mathrm{Ni}^{2+}$ transport by the human $\mathrm{Na}^{+}-\mathrm{Ca}^{2+}$ exchanger expressed in Sf9 cells. Am. J. Physiol. 276:C1184-C1192

Elias, C.L., Lukas, A., Shurraw, S., Scott, J., Omelchenko, A., Gross, G.J., Hnatowich, M., Hryshko, L. 2001. Inhibition of $\mathrm{Na}^{+}-\mathrm{Ca}^{2+}$ exchange by KB-R7943: transport mode selectivity and antiarrhythmic response. Am. J. Physiol. 281:H1334-H1345

Fujioka, Y., Komeda, M., Matsuoka, S. 2000. Stoichiometry of $\mathrm{Na}^{+}-\mathrm{Ca}^{2+}$ exchange in inside-out patches excised from guinea-pig ventricular myocytes. J. Physiol. 523:339-351

Fukushima, N., Ishii, I., Contos, J.J.A., Weiner, J.A., Chun, J. 2001. Lysophopspholipds receptors. Ann. Rev. Pharmacol. Toxicol. 41:507-534

Gómez, A.M., Schwaller, B., Porzig, H., Vassort, G., Niggli, E., Egger, M. 2002. Increased exchange current but normal $\mathrm{Ca}^{2+}$ transport via $\mathrm{Na}^{+}-\mathrm{Ca}^{2+}$ exchange during cardiac hypertrophy after myocardial infarction. Circ. Res. 91:323-330

Hale, C.C., Ebeling, E.G., Hsu, F.F., Ford, D.A. 1998. The selective activation of cardiac sarcolemmal sodium-calcium exchanger by plasmalogenic phosphatidic acid produced by phospholipase D. FEES Lett. 422:247-251

Hampton, T.G., Wang, J.F., DeAngelis, J., Amende, I., Philipson, K.D., Morgan, J.P. 2000. Enhanced gene expression of $\mathrm{Na}^{+}$$\mathrm{Ca}^{2+}$ exchanger attenuates ischemic and hypoxic contractile dysfunction. Am. J. Physiol. 279:H2846-H2854

Haworth, R.A., Goknur, A.B., Berkoff, H.A. 1989. Inhibition of $\mathrm{Na}^{+}-\mathrm{Ca}^{2+}$ exchange by general anesthetics. Circ. Res. 65:10211028

Hilgemann, D.W. 1990. Regulation and deregulation of cardiac $\mathrm{Na}^{+}-\mathrm{Ca}^{2+}$ exchange in giant excised sarcolemmal membrane patches. Nature. 344:242-245

Hilgemann, A. Collins, D.W. 1992. Mechanism of cardiac $\mathrm{Na}^{+}-$ $\mathrm{Ca}^{2+}$ exchange current stimulation by MgATP: possible in- volvement of aminophospholipid translocase. J. Physiol 454: 59-82

Hilgemann, D.W., Feng, S., Nasuhoglu, C. 2001. The complex and intriguing lives of $\mathrm{PIP}_{2}$ with ion channels and transporters. Science STKE. 111:RE19.

Hilgemann, D.W., Nicoll, D.A., Philipson, K.D. 1991. Charge movement during $\mathrm{Na}^{+}$translocation by native and cloned cardiac $\mathrm{Na}^{+} / \mathrm{Ca}^{2}$ exchanger. Nature 352:715-718

Hinata, M., Yamamura, H., Li, L., Watanabe, Y., Watano, T., Imaizumi, Y., Kimura, J. 2002. Reexamination of the stoichiometry of $\mathrm{Na}^{+} / \mathrm{Ca}^{2+}$ exchange with whole-cell voltage clamp of guinea pig ventricular myocytes. Ann. NY. Acad. Sci. USA 976: $154-156$

Hobai, L.A., O'Rourke, B. 2000. Enhanced $\mathrm{Ca}^{2+}$-activated $\mathrm{Na}^{+}$$\mathrm{Ca}^{2+}$ exchange activity in canine pacing-induced heart failure. Circ. Res. 87:690-698

Inoue, D., Pappano, A.J. 1983. L-Parmitylcarnitine and calcium ions act similarly on excitatory ionic currents in avian ventricular muscle. Circ Res. 52:625-634

Kang, T.M., Hilgemann, D.W. 2004. Multiple transport modes of the cardiac $\mathrm{Na}^{+}-\mathrm{Ca}^{2+}$ exchanger. Nature 427:544-548

Kimura, J., Miyamae, S., Noma, A. 1987. Identification of sodiumcalcium exchange current in single ventricular cells of guineapig. J. Physiol. 384:199-222

Kirby, M.S., Sagara, Y., Gaa, S., Inesi, G., Lederer, W.J., Rogers, T.B. 1992. Thapsigargin inhibits contraction and $\mathrm{Ca}^{2+}$ transient in cardiac cells by specific inhibition of the sarcoplasmic reticulum $\mathrm{Ca}^{2+}$ pump. J. BioL Chem. 267:1254512551

Lamers, J.M, Stinis, H.T, Montfoort, A, Hulsmann, W.C 1984. The effect of lipid intermediates on $\mathrm{Ca}^{2+}$ and $\mathrm{Na}^{+}$permeability and $\left(\mathrm{Na}^{+}, \mathrm{K}^{+}\right)$-ATPase of cardiac sarcolemmal. A possible role in myocardial ischemia. Biochim. Biophys. Acta. 774:127137

Leblanc, N., Hume, J.-R. 1990. Sodium current-induced release of calcium from cardiac sarcoplasmic reticulum. Science 248:372376

Luciani, S., Bova, S., Cargnelli, G., Cusinato, F., Debetto, P. 1991. Modulation of sodium-calcium exchange by lipids. Sodiumcalcium exchange: Proceedings of the Second International Conference. Ann. NY. Acad. Sci. USA. 639:156-165

Matsuoka, S., Nicoll, D.A., Reilly, R.F., Hilgemann, D.W., Philipson, K.D. 1993. Initial localization of regulatory regions of the cardiac sarcolemmal $\mathrm{Na}^{+}-\mathrm{Ca}^{2+}$ exchanger. Proc. Natl. Acad. Sci. U.S.A. 90:3870-3874

Matsuoka, S., Nicoll, D.A., He, Z.P., Philipson, K.D. 1997. Regulation of the cardiac $\mathrm{Na}^{+}-\mathrm{Ca}^{2+}$ exchanger by the endogenous XIP region. J. Gen. Physiol. 109:273-286

McHowatt, J., Yamada, K.A., Wu, J., Van, G.X., Corr, P.B. 1993. Recent insights pertaining to sarcolemmal phospholipids alterations underlying arrhythhmogenesis in the ischemic heart. J. Cardiovasc. Electrophysiol. 4:288-310

McKarns, S.C., Hansch, C., Caldwell, W.S., Morgan, W.T., Moore, S.K., Doolittle, D.J. 1997. Correlation between hydrophobicity of short-chain aliphatic alcohols and their ability to alter plasma membrane integrity. Fundam. Appl. Toxicol. 36:62-70

Mitra, R., Morad, M. 1985. A uniform enzymatic method for dissociation of myocytes from hearts and stomachs of vertebrates. Am. J. Physiol 249:H1056-H1060

Niggli, E. 1999. $\mathrm{Ca}^{2+}$ sparks in cardiac muscle: Is there life without them. NIPS 14:129-134

Niggli, E., Lederer, W.J. 1991. Molecular operations of the sodium-calcium exchanger revealed by conformation currents. Nature 349:621-624 
Niggli, E., Lederer, WJ. 1993. Activation of Na-Ca exchange current by photolysis of "caged calcium". Biophys. J. 65:882891

Niggli, E., Lipp, P. 1994. Voltage dependence of Na-Ca exchanger conformational currents. Biophys. J. 67:1516-1524

Philipson, K.D. 1984. Interaction of charged amphiphiles with $\mathrm{Na}^{+}-\mathrm{Ca}^{2+}$ exchanger in cardiac sarcolemmal vesicles. J. Biol. Chem. 259:13999-14002

Pogwizd, S.M., Schlotthauer, K., Li, L., Yuan, W., Bers, D.M. 2001. Arrhythmogenesis and contractile dysfunction in heart failure. Circ. Res. 88:1159-1167

Rakowski, R.F. 1993. Charge movement by the $\mathrm{Na} / \mathrm{K}$ pump in Xenopus oocytes. J. Gen. Physiol 101:117-144

Reeves, J.P., Hale, C.C. 1984. The stoichiometry of the cardiac sodium-calcium exchange system. J. Biol. Chem. 259:7733-7739
Simons, K., Toomre, D. 2000. Lipid rafts and signal transduction. Nature Rev. Mol. Cell Biol. 1:31-39

Van der Vusse, G.J., Van Bilsen, M., Reneman, R.S. 1994. Ischemia and reperfusion-induced alterations in membrane phospholipids: an overview. Ann. NY. Acad. Sci. USA 723:1-14

Vemuri, R., Philipson, K.D. 1988. Phospholipid composition modulates the $\mathrm{Na}^{+}-\mathrm{Ca}^{2+}$ exchanger activity of cardiac sarcolemma in reconstituted vesicles. Bochim. Biophys. Acta. 937:258-268

Watson, C.L., Gold, M.R. 1997. Lysophosphatidylcholine modulates cardiac $\mathrm{I}_{\mathrm{Na}}$ via multiple protein kinase pathways. Circ. Res. 81:387-395

$\mathrm{Xu}, \mathrm{Y}$. 2002. Sphingosylphosphorylcholine and lysophosphatidylcholine: $\mathrm{G}$ protein-coupled receptors and receptor-mediated signal transduction. Biochim. Biophys. Acta. 1582:81-88 